\title{
Iso-nuclear tungsten dielectronic recombination rates for use in magnetically-confined fusion plasmas
}

\author{
D.-H. Kwon ${ }^{\text {a }}$, W. Lee ${ }^{\mathrm{a}}$, S. Preval ${ }^{\mathrm{b}}$, C.P. Ballance ${ }^{\mathrm{c}, *}$, E. Behar ${ }^{\mathrm{d}}$, J. Colgan ${ }^{\mathrm{e}}$, C.J. Fontes ${ }^{\mathrm{e}}$, \\ T. Nakano ${ }^{f}$, B. Li $^{g}$, X. Ding ${ }^{\mathrm{h}}$, C.Z. Dong ${ }^{\mathrm{h}}$, Y.B. Fu ${ }^{\mathrm{h}}$, N.R. Badnell ${ }^{\mathrm{b}}$, M. O'Mullane ${ }^{\mathrm{b}}$, \\ H.-K. Chung ${ }^{\mathrm{i}}$, B.J. Braams ${ }^{1}$ \\ a Nuclear Data Center, Korea Atomic Energy Research Institute, Daejeon 305-353, Republic of Korea \\ ${ }^{\mathrm{b}}$ Department of Physics, University of Strathclyde, Glasgow G4 ONG, UK \\ ' School of Mathematics and Physics, Queen's University Belfast, BT7 1NN Northern Ireland, UK \\ d Physics Department, Technion Israel Institute of Technology, Technion City HAIFA 32000, Israel \\ e Los Alamos National Laboratory, Los Alamos, NM 87545, USA \\ ${ }_{\mathrm{f}}^{\mathrm{f}}$ Naka Fusion Institute, National Institutes for Quantum and Radiological Science and Technology, Ibaraki 311-019311, Japan \\ ${ }^{g}$ School of Nuclear Science and Technology, Lanzhou University, Lanzhou 730000, China \\ ${ }^{\text {h }}$ College of Physics and Electronic Engineering, Northwest Normal University, Lanzhou, China \\ ${ }^{\mathrm{i}}$ Atomic \& Molecular Data Unit, International Atomic Energy Agency, A-1400 Vienna, Austria
}

\section{A R T I C L E I N F O}

\section{Article history:}

Received 28 February 2017

Received in revised form 18 April 2017

Accepted 19 April 2017

Available online 5 June 2017

\section{Keywords:}

Dielectronic recombination

Radiative recombination

Tungsten

Iso-nuclear sequence

\begin{abstract}
A B S T R A C T
Under the auspices of the IAEA Atomic and Molecular Data Center and the Korean Atomic Energy Research Institute, our assembled group of authors has reviewed the current state of dielectronic recombination (DR) rate coefficients for various ion stages of tungsten (W). Subsequent recommendations were based upon available experimental data, first-principle calculations carried out in support of this paper and from available recombination data within existing atomic databases. If a recommendation was possible, data were compiled, evaluated and fitted to a functional form with associated uncertainty information retained, where available. This paper also considers the variation of the $\mathrm{W}$ fractional abundance due to the underlying atomic data when employing different data sets.
\end{abstract}

(C) 2017 Elsevier Inc. All rights reserved.

\footnotetext{
* Corresponding author.

E-mail address: C.Ballance@qub.ac.uk (C.P. Ballance).
} 


\section{Contents}

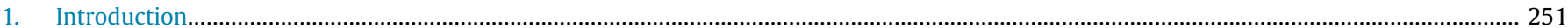

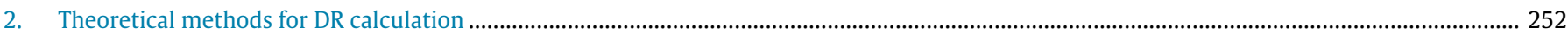

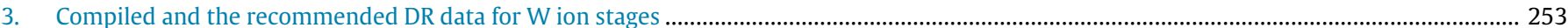

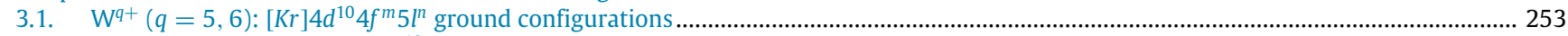

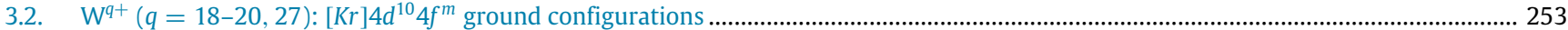

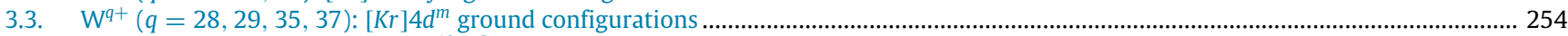

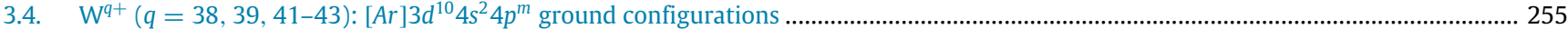

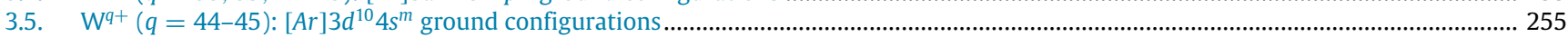

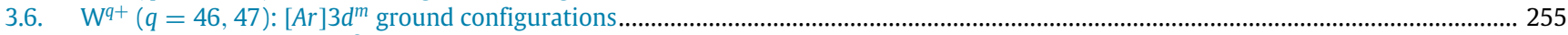

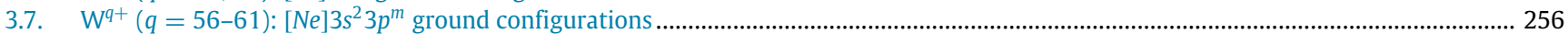

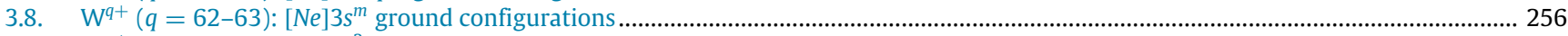

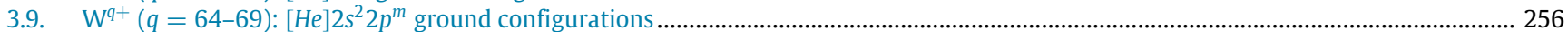

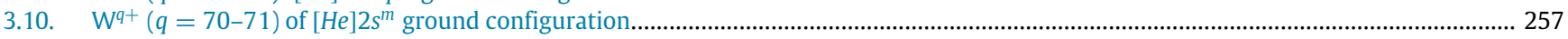

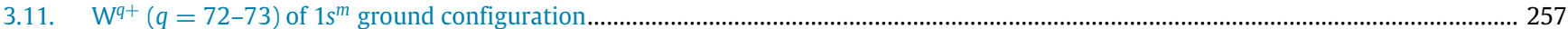

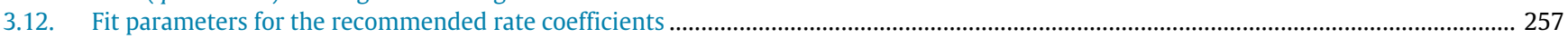

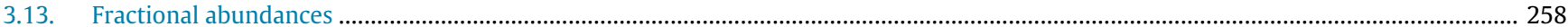

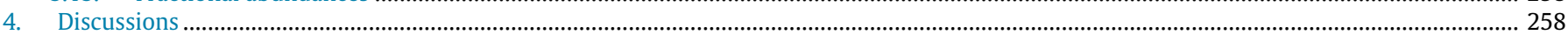

4.1. Resonance width at low energies: Chaotic mixing vs partitioned and damped approach ..................................................................... 258

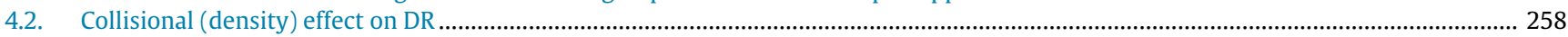

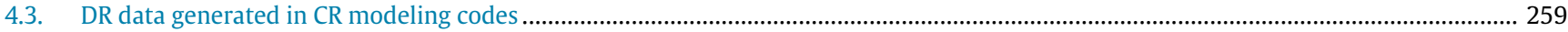

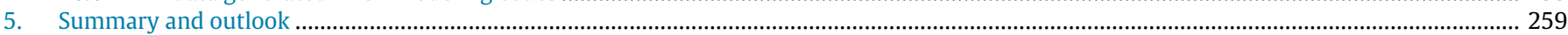

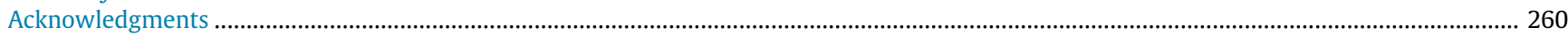

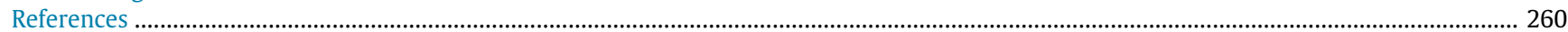

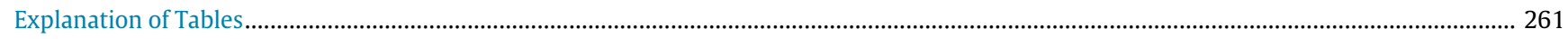

Table 1. Fit parameters for the recommended total DR Maxwellian rate coefficients of W ions. .............................................................. 261

\section{Introduction}

Tungsten (symbol W, nuclear charge $Z=74$ ) has been chosen as one of the plasma-facing materials in the divertor, a region of high predicted heat load in the ITER tokamak currently under construction in Cadarache, France. In preparation, other large-scale tokamak experiments such as JET have also adopted tungsten within their configuration in order to provide insight to projected ITER operational plasma conditions. Tungsten has several appealing characteristics as a plasma-facing material which include good heat conductivity, a high melting temperature, resistance to erosion and low affinity for tritium [1]. However, as a plasma impurity even highly charged tungsten ions in the core region of the tokamak may not be fully stripped of electrons and consequently radiation will constitute an important energy loss mechanism [2,3]. Therefore, characterization of this problem requires accurate collisional and radiative data for many ion stages and remains an issue of the utmost importance for the fusion community.

In magnetically-confined fusion the ionization balance is dominated by several competing electron-impact driven processes. On one hand we have direct ionization/excitation-autoionization and on the other we have recombination. Recombination may occur by either radiative recombination (RR) and/or dielectronic recombination (DR).

Tungsten, for many of the considered charge states, under ITER conditions of interest is a complicated many-electron problem; for example, in the temperature range of $3-5 \mathrm{keV}$, typical of the core plasma temperature in present experiments it is expected that nickel-like $\mathrm{W}^{46+}$ will be the most dominant abundant charge state. Alternatively in the temperature range of $15-20 \mathrm{keV}$ (representative of ITER core conditions) neon-like $\mathrm{W}^{64+}$ is expected to be the most abundant ion stage. Owing to the large number of intermediate Rydberg states involved in many of the Tungsten DR ion stages, it can be very computationally intensive to calculate certain ion stages using perturbative distorted-wave methods and therefore our review sometimes includes DR results from simpler empirical or semi-empirical models.
For plasma modeling of magnetically-confined plasmas valuable impurity influx data can be expressed in terms of effective rate coefficients for ionization and recombination from which the radiative power loss for each charge state may be calculated (assuming a Maxwellian plasma). These data are sufficient to calculate the collisional-ionization equilibrium and, in conjunction with a model inclusive of impurity source terms and impurity transport, to simulate the profile of an impurity charge state distribution for a given background plasma. This ultimately allows us to simulate the impurity effects on the radiative power balance. In general, effective rate coefficients are functions of electron temperature and density, but under certain low density conditions the coronal approximation may be appropriate.

In our following discussions and presentation of tables, we shall be referring to the following original sources. These are a mixture of semi-empirical formulae such as the Burgess General Formula through to distorted-wave methods as implemented within the HULLAC, FAC and AUTOSTRUCTURE codes, as well as selected $R$-matrix calculations. Distorted-wave methods provide the bulk of new calculations carried out in preparation of this paper.

The first comprehensive set of recombination rate coefficients for tungsten (and many other impurity ions) in fusion plasma DR was developed in 1976 at Princeton and Livermore [2,4]. These rate coefficients for dielectronic recombination were based on the Burgess general formula [5]. An average-ion model [4], was used as the basis for the computed rate coefficients, but the data that were published are derived quantities: average charge $\langle Z\rangle$, squared charge $\left\langle Z^{2}\right\rangle$, and radiative cooling rates as a function of electron temperature in a low density plasma. The rate coefficients themselves became widely used in fusion plasma modeling through the ADPAK set of subroutines that were included in the Multi-Ion Species Transport (MIST) code [6] and in several other transport codes; therefore the rate coefficients described originally in [4] are often called the ADPAK rates. In [4] the authors estimate their rate coefficients to be uncertain by a factor of $2-4$, and especially uncertain for high- $Z$ impurities.

A detailed comparison with EUV emissions in ASDEX-U pointed to problems with the ADPAK rates for tungsten. As expressed in [7]: 
"To obtain agreement between spectroscopic observations and predictions, the ionization rates for $\mathrm{W}$ ions with charge numbers larger than 30 had to be increased by a factor of up to 3 . The same result could have been obtained by reducing the recombination rates by the same factor". Asmussen et al. [7] chose to adjust the ionization rate coefficients because they conjectured that the original ADPAK rates had underestimated the effect of excitationautoionization. They provided a set of empirically adjusted rate coefficients (modified ADPAK) for ionization and recombination of $\mathrm{W}^{q+}(q=21-55)$.

The ADPAK rate coefficients were also the basis for the work of Ref. [8]. In their simulations of emission spectra on ASDEX$U$ they at first compared use of the original ADPAK data, the ADPAK data as modified by Asmussen, and the modified ADPAK recombination data with improved theoretical ionization rate coefficients obtained from the Configuration-Average DistortedWave (CADW) [9] method. Finally, their recommendation was to use the improved theoretical ionization data and the modified ADPAK recombination data incorporating an empirical scaling for each charge state. These recommended data were adopted by the Atomic Data and Analysis Structure (ADAS) database [10] and are therefore called either modified ADPAK rates with reference to [8] or simply as the ADAS rates.

We find that tungsten DR rates, which are dominant over RR process for the majority of the temperature range of tokamak operation (except for some extremely highly charged tungsten ions), are more scarce than the rates for RR in the literature. Although there is a complete set of recombination data within the ADAS database [10] it is currently derived from a simple semiempirical formula based on the half-century-old Burgess general formula $[4,5,8]$ as described above.

The remainder of this paper is organized as follows. In Section 2 we review the theoretical methods to obtain DR rate coefficients. The details of the recommended data for the compiled ion stages of W such as considered channels, methodologies, uncertainties, and comparison with other available data for DR rate coefficient are described. The recommended total DR rate coefficients are plotted together with the ADAS DR rate coefficients at the lowest electron density of $10^{11} \mathrm{~cm}^{-3}$ for the represented set of $\mathrm{W}$ ions in Section 3. The ADAS DR rate coefficients are obtained by subtracting $\mathrm{RR}$ rate coefficients from the total recombination rate coefficients in "adf11/acd50/acd50_w.dat" of the OPEN ADAS [11]. Along with the DR rate coefficients, the change of temperature range where the ion forms is presented from a calculation of the fractional abundance of $\mathrm{W}$ ions using recommended DR rate coefficients assuming a collisional ionization equilibrium [12]. For convenience of plasma modeling a set of fit parameters are also provided in Section 3. Current issues concerning DR that require further verification beyond the sharp resonance approximation, low electron density, and collisional ionization equilibrium are discussed in Section 4. Lastly, we summarize our results and state future work in Section 5.

\section{Theoretical methods for DR calculation}

The $\left(\mathrm{e}^{-}+\right.$ion $)$recombination process can occur directly by radiative recombination $(\mathrm{RR})$ :

$\mathrm{e}^{-}+\mathrm{A}^{q+} \longleftrightarrow\left[\mathrm{A}^{(q-1)+}\right]+\hbar \omega$

and also indirectly via intermediate autoionizing resonance levels by dielectronic recombination (DR) :

$\mathrm{e}^{-}+\mathrm{A}^{q+} \longleftrightarrow\left[\mathrm{A}^{(q-1)+}\right]^{* *} \longleftrightarrow\left[\mathrm{A}^{(q-1)+}\right]+\hbar \omega$.

The RR and DR processes, although they can share the initial and final levels, are often considered independently using theoretical semi-empirical or perturbative methods. The unified treatment of the RR and DR has been sought by some authors using nonperturbative methods [13-15], and by others using perturbative methods $[16,17]$. However, this treatment makes a negligible difference for the total recombination rates. Therefore, simpler and faster perturbative methods are preferred when the total rates are the main objective, such as in the present case.

Neglecting the interference between radiative recombination and dielectronic recombination as well as between DR resonances, the energy averaged DR cross section in an independent process, isolated resonance and distorted-wave (DW) approximation can be expressed in atomic units as

$\bar{\sigma}_{i j}=\bar{\sigma}_{i j}^{\mathrm{DC}} B_{j}$,

which is the product of the dielectronic capture cross section $\bar{\sigma}_{i j}^{\mathrm{DC}}$ for the recombining level $i$ to the intermediate resonance level $j$ and the radiative stabilizing branching ratio $B_{j}$ for the resonance level $j$. The dielectronic capture cross section $\bar{\sigma}_{i j}^{\text {DC }}$ can be written by

$\bar{\sigma}_{i j}^{\mathrm{DC}}=\frac{\pi^{2}}{E_{i j}} \frac{g_{j}}{2 g_{i}} A_{j i}^{a} \frac{\Gamma_{j} / 2 \pi}{\left(E-E_{i j}\right)^{2}+\Gamma_{j}^{2} / 4} \cong \frac{\pi^{2}}{E_{i j}} \frac{g_{j}}{2 g_{i}} A_{j i}^{a} \delta\left(E-E_{i j}\right)$,

where $g_{i}$ and $g_{j}$ are the statistical weights of the levels $i$ and $j$, respectively, $E_{i j}$ is the resonance energy, $A_{j i}^{a}$ is the autoionization rate from the level $j$ to $i$, and the total resonance width $\Gamma_{j}$ given by $\Gamma_{j}=\sum_{k} A_{j k}^{a}+\sum_{f} A_{j f}^{r}$ for autoionization rate $A_{j k}^{a}$ and radiative decay rate $A_{j f}^{r}$ from the level $j$ to any autoionization level $k$ and any radiative decay level $f$ is assumed to be much smaller than the resonance energy $E_{i j}$ i.e. $\Gamma_{j} \ll E_{i j}$ and the narrow Lorentzian profile is replaced with the Dirac delta function.

The radiative stabilizing branching ratio $B_{j}$ is given by

$B_{j}=\frac{\sum_{t} A_{j t}^{r}+\sum_{t^{\prime}} A_{j t^{\prime}}^{r} B_{t^{\prime}}}{\sum_{k} A_{j k}^{a}+\sum_{f} A_{j f}^{r}}$,

where $A_{j k}^{a}$ is the autoionization rate from the level $j$ to any ionized $k$ level, $A_{j f}^{r}$ is the radiative decay rate from the level $j$ to any radiatively decayed level $f$, the radiatively decayed levels $t$ and $t^{\prime}$ are below and above the ionization threshold, respectively, and $B_{t^{\prime}}$ is the branching ratio for radiative stabilization of the level $t^{\prime}$. For a detailed treatment of decays to autoionizing levels $\left(t^{\prime}\right)$ and their potential contribution to the DR rate, see Ref. [18].

In the sharp resonance approximation the DR rate coefficient averaged over a Maxwellian electron energy distribution at temperature $T_{\mathrm{e}}$ is given by $[13,19]$

$$
\begin{aligned}
\alpha_{i j}\left(T_{\mathrm{e}}\right) & =\frac{1}{\pi^{1 / 2}}\left(\frac{2}{T_{\mathrm{e}}}\right)^{3 / 2} \int_{0}^{\infty} \sigma_{i j}(E) \exp \left(-\frac{E}{T_{\mathrm{e}}}\right) E \mathrm{~d} E \\
& \cong \frac{1}{2 g_{i}}\left(\frac{2 \pi}{T_{\mathrm{e}}}\right)^{3 / 2} g_{\mathrm{j}} A_{j i}^{a} B_{j} \exp \left(-\frac{E_{i j}}{T_{\mathrm{e}}}\right) .
\end{aligned}
$$

The more rigorous unified approach to recombination would be to treat RR and DR concurrently, such as in $R$-matrix codes. Rydberg resonances are inherently included within the $R$-matrix method [20] and an $R$-matrix DR code is a simple extension of the photoionization work [21,22], which generates the bound-free matrix elements. By detailed balance arguments (the Milne relation) recombination rates can be calculated employing the same boundfree matrix elements. The distinction is that for recombination we have hundreds or thousands of bound (recombined) levels to consider while there is typically a single initial level to consider for photoionization. For highly charged levels, the $R$-matrix approach is significantly more computationally demanding as opposed to distorted-wave methods, as it implicitly assumes that the Rydberg resonances are fully resolved in $R$-matrix DR cross sections, which in turn implies a very fine energy mesh of approximately 
$10^{-6}$ Rydbergs. Although aggressive code parallelization of the $R$-matrix method has largely addressed this issue, the distortedwave methods are more efficient for these systems. The strength of the $R$-matrix method returns for the near-neutral systems of $\mathrm{W}$, where the precise position of resonances is determined from a large scale matrix diagonalization, which allows for the interference between resonances along the entire Rydberg sequence.

Atomic codes such as the Cowan code [23], AUTOSTRUCTURE [24], HULLAC [25], and FAC [26] have been adopted for the level-by-level DR calculations based on DW approximation for $\mathrm{W}$ ions. Configuration-average calculations with Dielectronic Recombination Average Configuration Using Local Approximation (DRACULA) code [27] has also been employed in the frame work of DW approximation. DARC [28] based on the $R$-matrix closecoupling approximation has been used to benchmark DR calculation for such a complex W ion system [29].

The branching ratio approach encapsulated by Eqs. (3)-(5), as well as the RM method, assumes that the plasma density is sufficiently low that the population of the autoionization levels are relatively small compared to those associated with the ground and low-lying metastable levels, i.e. the autoionization populations correspond to their coronal-equilibrium values. For sufficiently high densities, the CR modeling approach (see, for example, [30,31]) can be used to obtain density-dependent autoionization populations that are accurate beyond the coronal limit. In this case, level-resolved and total DR rate coefficients can be obtained by modifying the branching ratio in Eq. (5) to include explicit autoionization populations. This approach is discussed in more detail in Sections 4.2 and 4.3.

\section{Compiled and the recommended $D R$ data for $W$ ion stages}

\section{1. $W^{q+}(q=5,6):[K r] 4 d^{10} 4 f^{m} 5 l^{n}$ ground configurations}

There exist only DR calculations for $\mathrm{W}^{5+}$ and $\mathrm{W}^{6+}$ by Safronova et al. [32,33]. Excitation energies, radiative decay and autoionization rates, and level-resolved DR rates for intermediate resonance levels were calculated with Hartree-Fock relativistic (HFR) methods using the Cowan code. The total rate coefficients were obtained by the summation of the level resolved DR rates for all the included intermediate resonances. The accuracies for the excitation energies and radiative decay rates have been compared with Relativistic Many-body Perturbation Theory (RMBPT) [34] and HULLAC calculations. For autoionization energies and rates HULLAC calculations are used to assess the accuracy of the Cowan calculations.

Fig. 1 shows the total DR rate coefficients for $\mathrm{W}^{5+}$ and $\mathrm{W}^{6+}$. The DR resonances that were included for the $[\mathrm{Kr}] 4 \mathrm{~d}^{10} 4 \mathrm{f}^{14} 5 \mathrm{~s}^{2} 5 \mathrm{p}^{6} 5 \mathrm{~d}$ ground level of $\mathrm{W}^{5+}$ are $\Delta n_{c}=0$ channels of $5 \mathrm{~d} \rightarrow 5 l^{\prime}\left(l^{\prime}=\mathrm{d}, \mathrm{f}, \mathrm{g}\right)$, $5 \mathrm{p} \rightarrow 5 \mathrm{~d}, \Delta n_{c}=1$ channels of $5 \mathrm{~d} \rightarrow 6 l^{\prime}\left(l^{\prime}=\mathrm{s}, \mathrm{p}, \mathrm{d}\right), 5 \mathrm{p} \rightarrow$ $6 l^{\prime}\left(l^{\prime}=\mathrm{s}, \mathrm{p}, \mathrm{d}\right)$, and $4 \mathrm{f} \rightarrow 5 \mathrm{~d}$, and $\Delta n_{c}=2$ channels of $4 \mathrm{f} \rightarrow 6 \mathrm{~d}$ core excitations where $n_{c}$ denotes the principal quantum number of the core electron.

The captured electron $n l$ level is explicitly calculated for $n=5$ 7 and $l \leq 5$. For higher $n(n=8-100)$, the $1 / n^{3}$ scaling law for $A^{a}$ and $A^{r}$ and an asymptotic formula [32] for resonance energies were used. The calculated excitation energies exhibit agreement with the NIST recommended values to within $0.3-1.3 \%$, the calculated transition oscillator strengths exhibit $5-20 \%$ and $20-60 \%$ agreement with the Cowan, RMBPT and HULLAC calculations, respectively, and autoionization rates show $20-60 \%$ agreement between the Cowan and HULLAC calculations. Thus the resulting accuracy of the total rate coefficient using the HFR Cowan calculations can be estimated as $25-55 \%$ for lower temperatures and about a factor of 2 for $T_{e}>25 \mathrm{eV}$ [32].

For the $[\mathrm{Kr}] 4 \mathrm{~d}^{10} 4 \mathrm{f}^{14} 5 \mathrm{~s}^{2} 5 \mathrm{p}^{6}$ ground level of $\mathrm{W}^{6+}$, similar approaches were used to compute the total DR rate coefficients.

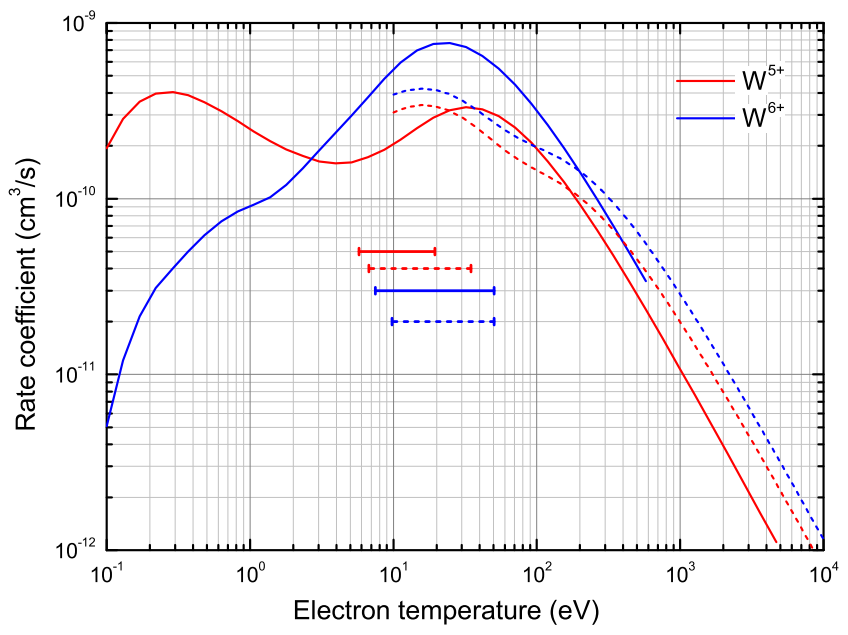

Fig. 1. Total DR rate coefficients for $W^{5+}[32]$ of the $[K r] 4 d^{10} 4 f^{14} 5 s^{2} 5 p^{6} 5 d$ ground level and $\mathrm{W}^{6+}[33]$ of the $[\mathrm{Kr}] 4 \mathrm{~d}^{10} 4 \mathrm{f}^{14} 5 \mathrm{~s}^{2} 5 \mathrm{p}^{6}$ ground level. The colored short dashed lines represent the corresponding ADAS DR rate coefficients. The horizontal bars indicate the temperature region of formation for each ion where fractional abundance is over $1 \%$. The solid horizontal bars represent the fractional abundance calculation using the present recommended DR data set and the dotted horizontal bars the fractional abundance calculation using the currently available ADAS total recombination data set. See the text of Section 3.13 for more details. (For interpretation of the references to color in this figure legend, the reader is referred to the web version of this article.)

$\Delta n_{c}=05 \mathrm{p} \rightarrow 5 l^{\prime}\left(l^{\prime}=d, f, g\right), \Delta n_{c}=15 \mathrm{p} \rightarrow 6 l^{\prime}\left(l^{\prime} \leq 4\right)$, $4 \mathrm{f} \rightarrow 5 l^{\prime}\left(l^{\prime}=d, f, g\right)$, and $\Delta n_{c}=24 \mathrm{f} \rightarrow 6 l^{\prime \prime}\left(l^{\prime \prime} \leq 4\right)$ core excitations were included in the total DR rate coefficient. The captured electron levels were treated with the same method as mentioned above. The accuracy of the total rate coefficient for $\mathrm{W}^{6+}$ is estimated to be about $25-55 \%$ for small temperatures and about a factor of 2 for $T_{e}>8 \mathrm{eV}$ [33].

\section{2. $W^{q+}(q=18-20,27):[K r] 4 d^{10} 4 f^{m}$ ground configurations}

Experimental measurements of DR rate coefficients using the TSR were performed for $\mathrm{W}^{18+}-\mathrm{W}^{21+}[35]$. The experimental and theoretical results for $\mathrm{W}^{18+}$ [36], $\mathrm{W}^{19+}$ [37], and $\mathrm{W}^{20+}$ [38] have been published but the analysis of the data for $W^{21+}$ is still in progress.

For $\mathrm{W}^{18+}$ the experimental data and intermediate-coupling AUTOSTRUCTURE calculations were found to differ by about a factor of $1-3$ at low temperatures (below $\sim 100 \mathrm{eV}$ ), but at higher temperatures (over $\sim 100 \mathrm{eV}$ ) the experimental and theoretical results were in good agreement [36]. The AUTOSTRUCTURE calculations are an extension of the approach used for $\mathrm{W}^{20+}$ [39] and include $\Delta n_{c}=0$ and $\Delta n_{c}=1$ core excitations of $4 \mathrm{~d}$ and $4 \mathrm{f}$ electrons from the ground level $[\mathrm{Kr}] 4 \mathrm{~d}^{10} 4 \mathrm{f}^{10}$. The total experimental rate coefficient was reported for temperatures from 1 to $1000 \mathrm{eV}$ and the estimated total relative uncertainty of the experimentally derived rate coefficient (including the missing resonance strength from high $n$ levels above $300 \mathrm{eV}$ ) is around $37 \%$ at a temperature of $150 \mathrm{eV}$. The contribution of the missing resonances to the total DR rate coefficient is less than $5 \%$ at $1000 \mathrm{eV}$ and no more than $1 \%$ at $1 \mathrm{eV}$. The estimated total relative uncertainty at a temperature of $10 \mathrm{eV}$ is $10 \%$. The red line in Fig. 2 represents the total rate coefficient, which combines the experimental total rate coefficient with FLYCHK [40] scaling of the total rate coefficient at temperatures over $1000 \mathrm{eV}$.

For $\mathrm{W}^{20+}$ the experimental data and the intermediate-coupling AUTOSTRUCTURE calculations are found to differ by about factor of 3 at low temperatures (below $\sim 10 \mathrm{eV}$ ) [38]. The theoretical 


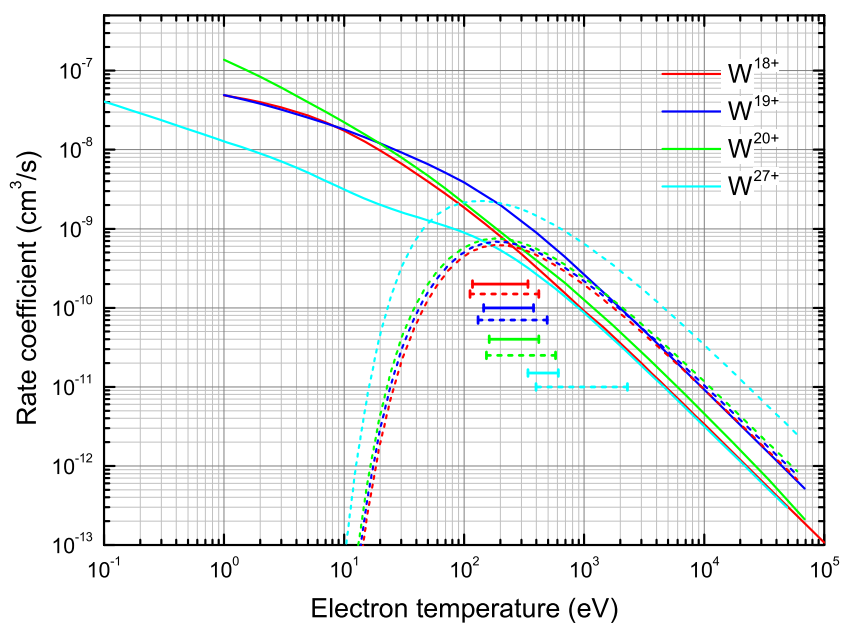

Fig. 2. Total DR rate coefficients for $W^{18+}[36,40]$ of the $[\mathrm{Kr}] 4 \mathrm{~d}^{10} 4 \mathrm{f}^{10}$ ground level, $\mathrm{W}^{19+}[37]$ of the $[\mathrm{Kr}] 4 \mathrm{~d}^{10} 4 \mathrm{f}^{9}$ ground level, $\mathrm{W}^{20+}[38,41]$ of the $[\mathrm{Kr}] 4 \mathrm{~d}^{10} 4 \mathrm{f}^{8}$ ground level, and $\mathrm{W}^{27+}[42]$ of the $[\mathrm{Kr}] 4 \mathrm{~d}^{10} 4 \mathrm{f}$ ground level. The solid and dotted horizontal bars represent the same as in Fig. 1. (For interpretation of the references to color in this figure legend, the reader is referred to the web version of this article.)

calculations include $\Delta n_{c}=0$ and $\Delta n_{c}=1$ core excitations of $4 \mathrm{~d}$ and $4 \mathrm{f}$ electrons from the ground level $[\mathrm{Kr}] 4 \mathrm{~d}^{10} 4 \mathrm{f}^{8}$. The captured electron $n l$ level is explicitly calculated up to $n=100$ and $l \leq 5-7$ without any extrapolation and the convergence is estimated to be within $1-3 \%$. The experiment only detects resonances which occur below $140 \mathrm{eV}$ and a theoretical top-up (for resonances above $140 \mathrm{eV}$ ) is added to the experimental result to estimate the total rate coefficient. The systematic uncertainty for the experimental rate coefficient at temperatures below $100 \mathrm{eV}$ is about 20\% [38]. The green line in Fig. 2 represents the experimental total rate coefficient topped-up with the theoretical high-energy resonances for temperatures from 1 to $100 \mathrm{eV}$ and is combined with an updated intermediate-coupling calculation [41] at temperatures greater than $690 \mathrm{eV}$.

It is noted that for $\mathrm{W}^{19+}$ the experimental data and the theoretical calculations performed using the configuration-average AUTOSTRUCTURE method, combined with the partitioned damped approach considering Breit-Wigner statistical redistribution for autoionizing widths, exhibit good agreement [37]. The partitioned damped approach will be described in more detail in Section 4.

For $\mathrm{W}^{27+}$, which has a ground level $[\mathrm{Kr}] 4 \mathrm{~d}^{10} 4 \mathrm{f}$, relativistic jj-coupling FAC calculations were performed as discussed in detail by [42] and the cyan line in Fig. 2 represents the result [43]. The calculations include the autoionizing inner-shell excited configuration complexes: $4 \mathrm{~d}^{9} 4 \mathrm{f}^{2} \mathrm{nl}(4 \mathrm{~d}-4 \mathrm{f}), 4 \mathrm{~d}^{9} 4 \mathrm{f} 5 l^{\prime} n l\left(4 \mathrm{~d}-5 l^{\prime}\right), 4 \mathrm{~d}^{10} 5 l^{\prime} n l$ $\left(4 \mathrm{f}-5 l^{\prime}\right), 4 \mathrm{~d}^{10} 6 l^{\prime} n l\left(4 \mathrm{f}-6 l^{\prime}\right)$ and $4 \mathrm{p}^{5} 4 \mathrm{~d}^{10} 4 \mathrm{f}^{2} n l(4 \mathrm{p}-4 \mathrm{f})(n \leq 18$, $l \leq 5)$. These resonant configurations are associated with $\Delta n_{c}=0$ excitations from the $4 \mathrm{p}$ and $4 \mathrm{~d}$ subshells, $\Delta n_{c}=1$ excitations from the $4 \mathrm{~d}$ and $4 \mathrm{f}$ subshells as well as $\Delta n_{c}=2$ core excitations from the $4 \mathrm{f}$ subshells. Energy levels, radiative transition probabilities and autoionization rates were calculated using the FAC code up to $n \leq 18$ and $l \leq 5$, and the contributions from higher- $n$ levels were extrapolated up to $n=1000$. Based on previous studies it was estimated that contributions from $4 \mathrm{p}-5 l^{\prime}, 4 \mathrm{~d}-6 l^{\prime}$, and $4 \mathrm{p}-6 l^{\prime}$ complexes are small and may be neglected [43].

\section{3. $W^{q+}(q=28,29,35,37):[K r] 4 d^{m}$ ground configurations}

For $\mathrm{W}^{28+}$, which has a ground level $[\mathrm{Kr}] 4 \mathrm{~d}^{10}, \mathrm{FAC}$ calculations were also performed by [42] and the red line in Fig. 3 represents the result [43]. The doubly excited configurations $4 d^{9} 4 \mathrm{fnl}(4 \mathrm{~d}-4 \mathrm{f})$, $4 \mathrm{~d}^{9} 5 l^{\prime} n l\left(4 \mathrm{~d}-5 l^{\prime}\right)$ and $4 \mathrm{~d}^{9} 6 l^{\prime} n l\left(4 \mathrm{~d}-6 l^{\prime}\right)$ as well as $4 \mathrm{p}^{5} 4 \mathrm{~d}^{10} 4 \mathrm{f} n l(4 \mathrm{p}-$

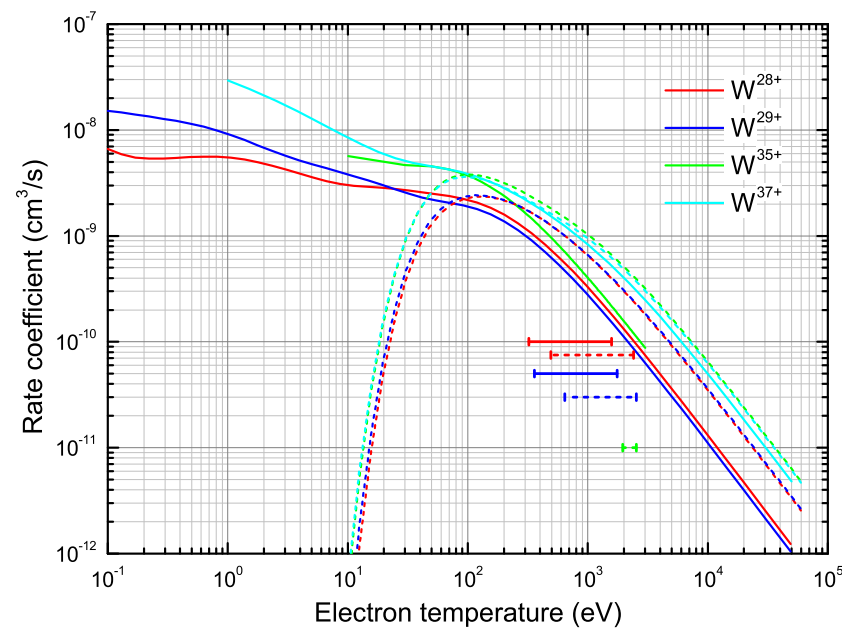

Fig. 3. Total DR rate coefficients for $\mathrm{W}^{28+}[43]$ of the $[\mathrm{Kr}] 4 \mathrm{~d}^{10}$ ground level, $\mathrm{W}^{29+}[43]$ of the $[\mathrm{Kr}] 4 \mathrm{~d}^{9}$ ground level, $\mathrm{W}^{35+}[29]$ of the $[\mathrm{Kr}] 4 \mathrm{~d}^{3}$ ground level, and $\mathrm{W}^{37+}[45]$ of the $[\mathrm{Kr}] 4 \mathrm{~d}$ ground level. The solid and dotted horizontal bars represent the same as in Fig. 1. (For interpretation of the references to color in this figure legend, the reader is referred to the web version of this article.)

4f) and $4 \mathrm{p}^{5} 4 \mathrm{~d}^{10} 5 l^{\prime} n l\left(4 \mathrm{p}-5 l^{\prime}\right)$ were included in the calculations. Energy levels, radiative transition probabilities and autoionization rates were calculated up to $n \leq 18$ and $l \leq 6$, and the contributions from higher- $n$ levels were extrapolated up to $n=1000$. An ab-initio calculation by Safronova et al. [44] using the HFR method via the Cowan code is also available, but the total rate coefficient predicted from this calculation is about ten times smaller than that of ADAS, FLYCHK, and other predictions from CR modeling, as well as the FAC calculation at temperatures over $500 \mathrm{eV}$. This is most likely due to omission of significant resonances [43]. Thus the FAC data, since it agrees well with the other predictions at high temperatures, is recommended.

For $\mathrm{W}^{29+}, \Delta n_{c}=0,1,2$ core excitations of $4 \mathrm{~d}$ and $4 \mathrm{p}$ electrons from the ground level $[\mathrm{Kr}] 4 \mathrm{~d}^{9}$ were included in the FAC calculations of [42]. The captured electron $n l$ level is explicitly calculated up to $n=18$ and $l \leq 5$, and for higher $n(n=19-1000)$ a simple scaling law [44] was used. The blue line in Fig. 3 represents recently updated data [42], where in addition to earlier calculations, the rate coefficient close to the near-threshold region was also determined.

For $\mathrm{W}^{35+}$, the CADW method used by the DRACULA code was compared for $4 \mathrm{~d} \rightarrow 4 \mathrm{f}$ and $4 \mathrm{p} \rightarrow 4 \mathrm{~d}$ excitations of the $[\mathrm{Kr}] 4 \mathrm{~d}^{3}$ ground state with both the level-resolved DW and Dirac $R$-matrix methods [29]. At high temperatures over $100 \mathrm{eV}$ the CADW result agrees well with both the level-resolved DW and Dirac $R$-matrix results.

At low temperatures, the level-resolved DW and $R$-matrix calculations differ from the CADW result. This is due to the inclusion of resonances within the ground state complex $4 \mathrm{~d}^{3} \mathrm{nl}$ included in the $R$-matrix and level-resolved distorted-wave AUTOSTRUCTURE calculations, but not the CADW calculations. The differences between the level-resolved DW and the $R$-matrix result for the $\Delta n_{c}=0,4 \mathrm{~d}-4 \mathrm{f}$ excitation are minimal. For the $\Delta n_{c}=0,4 \mathrm{p}-$ $4 \mathrm{~d}$ transition the variation in resonance positions from the two independent calculations produces an enhanced $R$-matrix rate at lower temperatures, however the $R$-matrix rate coefficients are in reasonable agreement with the DW calculations by $100 \mathrm{eV}$.

For $\mathrm{W}^{37+}, \Delta n_{c}=0,1,2$ core excitations of $4 \mathrm{l}(4 \mathrm{~s}, 4 \mathrm{p}$, and $4 \mathrm{~d}$ ) electrons and $\Delta n_{c}=0,1,2$ core excitations of $3 l$ (3s, 3p, and $3 \mathrm{~d}$ ) electrons from the ground level $[\mathrm{Kr}] 4 \mathrm{~d}$ were included in the FAC calculations of [45]. The captured electron $\mathrm{nl}$ level is explicitly calculated up to $n=18$ and $l \leq 12$ for the core excitation of the $4 l$ electrons and $n=16$ and $l \leq 9$ for the core 


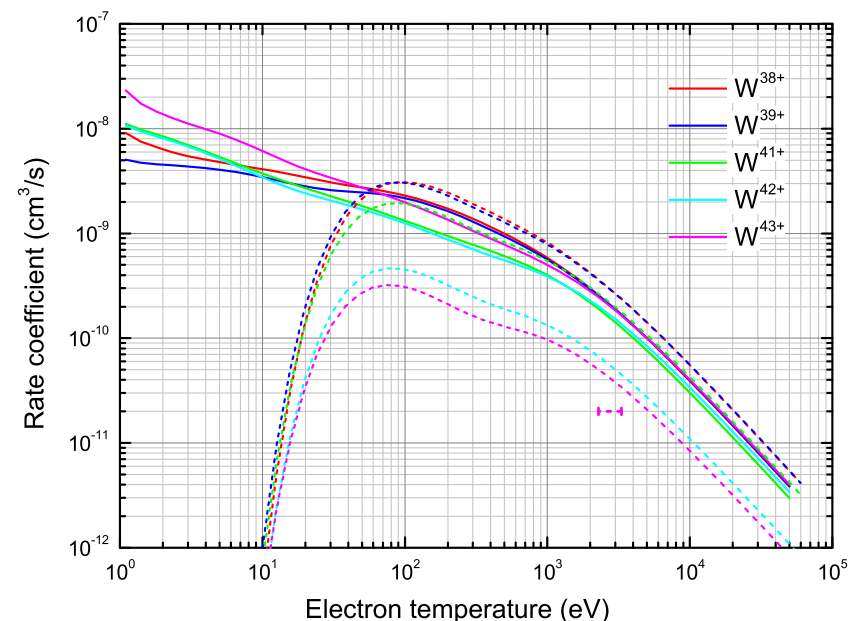

Fig. 4. Total DR rate coefficients for $W^{38+}$ of the $[A r] 3 d^{10} 4 s^{2} 4 p^{6}$ ground level, $W^{39+}$ of the $[\operatorname{Ar}] 3 \mathrm{~d}^{10} 4 \mathrm{~s}^{2} 4 \mathrm{p}^{5}, \mathrm{~W}^{41+}$ of the $[\operatorname{Ar}] 3 \mathrm{~d}^{10} 4 \mathrm{~s}^{2} 4 \mathrm{p}^{3}$ ground level, $\mathrm{W}^{42+}$ of the $[A r] 3 d^{10} 4 s^{2} 4 p^{2}$ ground level, and $W^{43+}$ of the [Ar] $3 d^{10} 4 s^{2} 4 p$ ground level [47]. The solid and dotted horizontal bars represent the same as in Fig. 1. (For interpretation of the references to color in this figure legend, the reader is referred to the web version of this article.)

excitation of the $3 l$ electrons, respectively. For the higher $n$ values a simple extrapolation [46] of the $1 / n^{3}$ scaling law was used. The cyan line of Fig. 3 represents the total rate coefficient for this ion. The promotion of an inner-shell $3 l$ electron and $\Delta n_{c}=2$ core excitations of $3 l$ and $4 l$ electrons have negligible contributions to the rate coefficient at temperatures below $\sim 100 \mathrm{eV}$, but become significant at higher temperatures over $\sim 1000 \mathrm{eV}$.

$$
\begin{aligned}
& \text { 3.4. } W^{q+}(q=38,39,41-43):[A r] 3 d^{10} 4 s^{2} 4 p^{m} \text { ground configura- } \\
& \text { tions }
\end{aligned}
$$

Ab-initio data for $\mathrm{W}^{q+}(q=38-43$ except for $q=40)$ from FAC calculations are available. The calculations include $\Delta n_{c}=$ $0,1,2$ core excitations of $3 l(3 \mathrm{~s}, 3 \mathrm{p}$, and $3 \mathrm{~d}$ ) electrons, as well as $4 l(4 \mathrm{~s}$ and $4 \mathrm{p})$ electrons, from the ground level $[\mathrm{Ar}] 3 \mathrm{~d}^{10} 4 \mathrm{~s}^{2} 4 \mathrm{p}^{m}$ in a similar manner as the $\mathrm{W}^{37+}$ calculations [47]. The total DR rate coefficients for these ions are illustrated in Fig. 4 by colored solid lines which are compared with the available data from the ADAS data set (indicated by short-dashed colored lines). The captured electron levels are explicitly calculated up to $n=18$ for the core excitation of the $4 l$ electrons, and $n=16$ for the core excitation of the $3 l$ electrons. For the higher $n$ levels, an extrapolation formula of the $1 / n^{3}$ scaling law was applied.

For the $\mathrm{W}^{38+}$ and $\mathrm{W}^{39+}$ ions, the $4 \mathrm{p}$ electron excitation has the largest contribution to the total DR coefficient, but the contributions from 3d and 3p electron excitations should be retained, especially in the high temperature region above $500 \mathrm{eV}$ [48]. For $\mathrm{W}^{41+}, 4 \mathrm{~s}$ and $4 \mathrm{p}$ excitations have similar contributions to the total DR coefficients, while $n=3$ excitations have significant contributions in the high temperature region above about $1 \mathrm{keV}$. For $\mathrm{W}^{42+}$ and $\mathrm{W}^{43+}$, with the opening of the $4 \mathrm{~s}$ electron channel, the 4 s excitation becomes the most important contribution to the total DR coefficient [49].

\section{5. $W^{q+}(q=44-45):[A r] 3 d^{10} 4 s^{m}$ ground configurations}

Total DR rate coefficients are available for the $\mathrm{W}^{44+}$ ion, which has the $[\mathrm{Ar}] 3 \mathrm{~d}^{10} 4 \mathrm{~s}^{2}$ ground level $[47,50]$, and for $\mathrm{W}^{45+}[51,52]$, which has the $[\mathrm{Ar}] 3 \mathrm{~d}^{10} 4 \mathrm{~s}$ ground level, from FAC calculations. For $\mathrm{W}^{44+} \Delta n_{c}=0,1,2$ core excitations of the $4 \mathrm{~s}$ electron and $\Delta n_{c}=1,2$ core excitations of the $3 \mathrm{l}$ (3s, 3p, and 3d) electrons

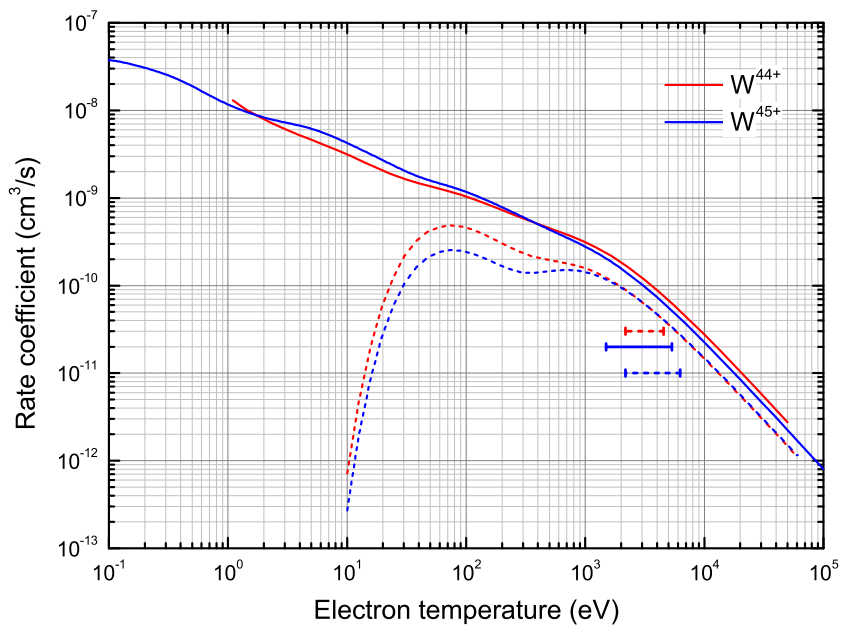

Fig. 5. Total DR rate coefficients for $\mathrm{W}^{44+}[47]$ of the $[\mathrm{Ar}] 3 \mathrm{~d}^{10} 4 \mathrm{~s}^{2}$ ground level and for $\mathrm{W}^{45+}[50-52]$ of the $[\mathrm{Ar}] 3 \mathrm{~d}^{10} 4 \mathrm{~s}$ ground level. The colored short dashed lines and the horizontal bars represent same as in Fig. 1. (For interpretation of the references to color in this figure legend, the reader is referred to the web version of this article.)

are included in the total rate coefficient. The captured electron levels were explicitly calculated up to $n=7$ and for the higher $n>7$ contributions an extrapolation by the $1 / n^{3}$ scaling law for $A^{a}$ and $A^{r}$ was used [47]. A more sophisticated calculation, which considered configuration mixing (CM, or so called configurationinteraction) involving double core excitations for $\Delta n_{c}=0,1$ and Decays to Autoionizing levels, possibly followed by Cascades (DAC, see Ref. [18]) was also carried out [50]. The CM and DAC effects on the total rate coefficient are around $\sim 30 \%$. The red line in Fig. 5 represents the rate coefficient from the FAC calculations [47].

For $\mathrm{W}^{45+}$ partial DR rate coefficients via the $3 \mathrm{p}^{6} 3 \mathrm{~d}^{9} 4 l 4 l^{\prime} 4 l^{\prime \prime}$ and $3 \mathrm{p}^{5} 3 \mathrm{~d}^{10} 4 l 4 l^{\prime} 4 l^{\prime \prime}$ configurations are available from HULLAC calculations [53]. The total rate coefficient was subsequently obtained [50-52] and these partial DR rates coefficients agree with the former results [53]. The data by Kwon \& Lee [50,51] at low temperatures below $2000 \mathrm{eV}$ and by Nakano [52] at temperatures over $2000 \mathrm{eV}$ was used for the recommended data set, since $\Delta n_{c}=$ 0 core excitation of the $4 \mathrm{~s}$ electron, which dominates the low temperature DR region, was treated more accurately by Kwon \& Lee [50,51]. The $\Delta n_{c}>2$ core excitations of the $3 l$ and $4 l$ electrons are non-negligible at high temperatures and were included by Nakano [52]. The blue line in Fig. 5 represents the rate coefficient from the two FAC calculations [50-52]. It is noted that the total DR rate coefficient for $\mathrm{W}^{45+}$ was obtained in a similar manner to that of $\mathrm{W}^{5+}$ and $\mathrm{W}^{6+}$ by Safronova et al. [54]. Again, these rate coefficients are much smaller than the recommended data set since some significant DR channels for $\Delta n_{c}=0,1$ core excitations appear to have been omitted [51].

\section{6. $W^{q+}(q=46,47):[A r] 3 d^{m}$ ground configurations}

DR data from ab-initio calculations exist only for $\mathrm{W}^{46+}$ and $\mathrm{W}^{47+}$. For $\mathrm{W}^{46+}$ the total rate coefficient is available from HULLAC calculations [55]. $\Delta n_{c}=1$ core excitations of the $3 l$ (3s, 3p, and $3 d$ ) electrons from the ground level $[\mathrm{Ar}] 3 \mathrm{~d}^{10}$ are included in the total rate coefficient. The captured electron $n l^{\prime}$ levels were explicitly calculated up to $n=9$ for the 3 d core excitation and $n=5$ for the $3 \mathrm{~s}$ and $3 \mathrm{p}$ core excitations. For the higher $n$ values an extrapolation by $1 / n^{3}$ scaling law was used [56]. The total rate coefficient agrees well with those from Cowan calculations [57] and from FAC calculations [50], except at low temperatures below $10 \mathrm{eV}$. At low temperatures, the DR rate coefficient is very sensitive 


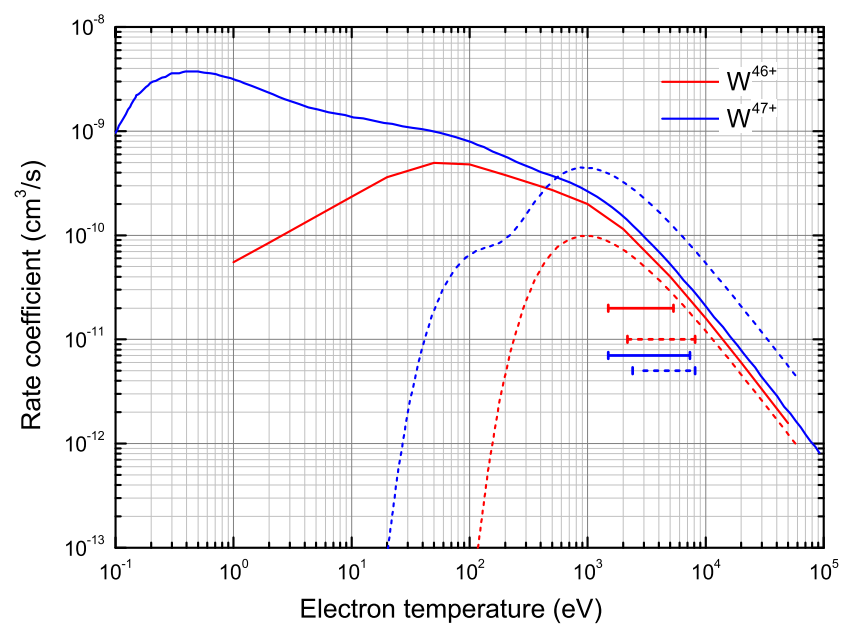

Fig. 6. Total DR rate coefficients for $\mathrm{W}^{46+}[55]$ of the $[\mathrm{Ar}] 3 \mathrm{~d}^{10}$ ground level and for $\mathrm{W}^{47+}[46]$ of the $[\mathrm{Ar}] 3 \mathrm{~d}^{9}$ ground level. The dotted horizontal bars represent the same as in Fig. 1. (For interpretation of the references to color in this figure legend, the reader is referred to the web version of this article.)

to resonance structure, depending on CM and the detailed wavefunctions, leading to a very large uncertainty in the result [50]. The red line in Fig. 6 represents the total rate coefficient obtained from HULLAC [55].

For $\mathrm{W}^{47+}$ (ground level $[\mathrm{Ar}] 3 \mathrm{~d}^{9}$ ) the total rate coefficient is available from FAC calculations [46] and includes $\Delta n_{c}=0$ and 1 core excitations of the $3 l$ (3s, 3p, and $3 d$ ) electrons and $\Delta n_{c}=2$ core excitation of $3 \mathrm{~d}$ electron from the ground level. The captured electron $n l^{\prime}$ levels were explicitly calculated up to $n=9$ for the $\Delta n_{c}=2$ core excitations and $n=25$ for the $\Delta n_{c}=0$ and 1 core excitations. $l^{\prime} \leq 12$ for the $\Delta n_{c}=0$ core excitation and $l^{\prime} \leq 8$ for $\Delta n_{c}=1$ and 2 core excitations were included. The DAC process was also considered. For the higher $n$ values an extrapolation treating the DAC process was used [46]. The blue line in Fig. 6 represents the total rate coefficient from the FAC calculations [46].

\section{7. $W^{q+}(q=56-61):[N e] 3 s^{2} 3 p^{m}$ ground configurations}

The total rate coefficient for $\mathrm{W}^{q+}(q=56-61)$ has been computed using the intermediate-coupling AUTOSTRUCTURE code [58]. Core excitations with $\Delta n_{c}=0,1$, and 2 were included in the total DR rate coefficient for these ionization stages. For $\Delta n_{c}=0$, excitations of $3 \mathrm{~s} \rightarrow 3 l$ and $3 \mathrm{p} \rightarrow 3 l$ were included. For $\Delta n_{c}=1$, excitations of $2 \mathrm{p} \rightarrow 3 l$, $3 \mathrm{~s} \rightarrow 4 l$, and $3 \mathrm{p} \rightarrow 4 l$ were included. Finally, for $\Delta n_{c}=2$, excitations of $3 \mathrm{~s} \rightarrow 5 \mathrm{l}$ and $3 \mathrm{p} \rightarrow$ $5 l$ were included. For all of these core excitations, configurations that strongly mix were included in the structure and DR calculations through the "one-up/one-down" rule. For example, the "one-up/one-down" configurations for $3 s 3 p^{4} 3 d$ will be $3 s^{2} 3 p^{2} 3 d^{2}$ and $3 \mathrm{p}^{6}$. For each core excitation, DR rate coefficients were calculated explicitly up to $n=25$, and then for quasi-logarithmic values of $n$ up to $n=1000$. Interpolation was then used to generate the intermediate $n$ values. $l$ values were included so as to numerically converge the total DR rate coefficient for each core excitation to $<1 \%$ over the ADAS temperature range $\left(10 z^{2}-10^{6} z^{2}\right.$, where $z$ is the residual charge).

For $\mathrm{W}^{56+}$ the total rate coefficient computed using HULLAC is also available [59]. $\Delta n_{c}=0$ and 1 core excitations of 3 s and $3 p$ electrons, $\Delta n_{c}=1$ core excitations of $2 \mathrm{~s}$ and $2 \mathrm{p}$ electrons, and $\Delta n_{c}=2$ core excitation of the $3 p$ electron from the ground level $[\mathrm{Ne}] 3 \mathrm{~s}^{2} 3 \mathrm{p}^{6}$ are included in the total rate coefficient. The captured electron $n l^{\prime}$ levels were explicitly calculated up to $n=18,17,12$,

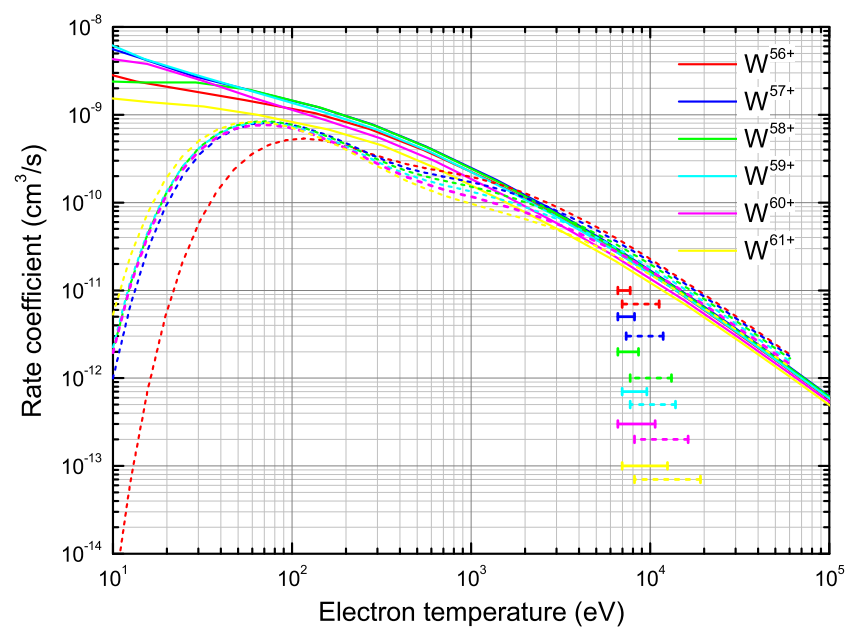

Fig. 7. Total DR rate coefficients for $\mathrm{W}^{q+}(q=56-61)$ of the $[\mathrm{Ne}] 3 \mathrm{~s}^{2} 3 p^{m}(m=6-1)$ ground level [58]. The solid and dotted horizontal bars represent the same as in Fig. 1. (For interpretation of the references to color in this figure legend, the reader is referred to the web version of this article.)

8 , and 5 for the $\Delta n_{c}=0$ core excitations of $3 \mathrm{~s}$ and $3 p$ electrons, $3 \mathrm{p} \rightarrow 4 \mathrm{l}$ core excitation, $3 \mathrm{~s} \rightarrow 4 \mathrm{l}$ core excitation, $2 \mathrm{p} \rightarrow 3 \mathrm{~d}$ core excitation, $2 \mathrm{~s} \rightarrow 3 \mathrm{~d}$ core excitation, and $3 \mathrm{p} \rightarrow 5 \mathrm{l}$ core excitation, respectively, all with $l^{\prime} \leq 8$. DAC is negligible and was not included in the DR calculation. For the higher $n$ values an extrapolation using $1 / \mathrm{n}^{3}$ scaling and constant law mixture [56] considering slow convergence was used [59] except for the $3 p \rightarrow$ $5 l$ core excitation. For this $3 \mathrm{p} \rightarrow 5 l$ core excitation only $5 l^{\prime}$ captured electron levels were included in the total DR rate, because the higher $n l^{\prime}$ level contribution is negligible. The total rate coefficient for $\mathrm{W}^{56+}$ using AUTOSTRUCTURE [58] agrees well with the HULLAC calculation, except for some deviation in the low-temperature region below $100 \mathrm{eV}$. The colored lines in Fig. 7 represent the total rate coefficients for $\mathrm{W}^{q+}(q=56-61)$ computed using AUTOSTRUCTURE [58].

\section{8. $W^{q+}(q=62-63):[N e] 3 s^{m}$ ground configurations}

The total rate coefficient for $\mathrm{W}^{q+}(q=62-63)$ has also been computed using AUTOSTRUCTURE [58]. The total DR rate coefficients for $3 \mathrm{~s}^{m}$ were calculated in a similar manner to that described in Section 3.7. Core excitations with $\Delta n_{c}=0,1$, and 2 were included in the total DR rate coefficients. For $\Delta n_{c}=0$, excitations of $3 \mathrm{~s} \rightarrow 3 l$ were included. For $\Delta n_{c}=1$, core excitations of $2 \mathrm{p} \rightarrow 3 \mathrm{l}$ and $3 \mathrm{~s} \rightarrow 4 \mathrm{l}$ were included. For $\Delta n_{c}=2$, core excitations of $3 \mathrm{~s} \rightarrow 5 l$ were included. As in Section 3.7, one up-one down mixing configurations were included for each core excitation, and the $n l$ values computed were as described in Section 3.7. Numerical convergence of the DR rate total to $<1 \%$ was again achieved for the ADAS temperature range. For $\mathrm{W}^{63+}$ the total rate coefficient was also computed using the HFR Cowan calculation [60] but is much smaller than the AUTOSTRUCTURE calculation at temperatures below $1000 \mathrm{eV}$. The red and blue lines in Fig. 8 represent the total rate coefficients for $\mathrm{W}^{62+}$ and $\mathrm{W}^{63+}$ computed using AUTOSTRUCTURE.

\section{9. $W^{q+}(q=64-69):[H e] 2 s^{2} 2 p^{m}$ ground configurations}

The total rate coefficient for $\mathrm{W}^{q+}(q=64-69)$ has been computed using AUTOSTRUCTURE [58]. For the $2 \mathrm{p}^{m}$ configurations, core excitations with $\Delta n_{c}=0,1$ were included in the total DR rate coefficient calculation with the exception of $2 \mathrm{p}^{6}$, where $\Delta n_{c}=1$, 


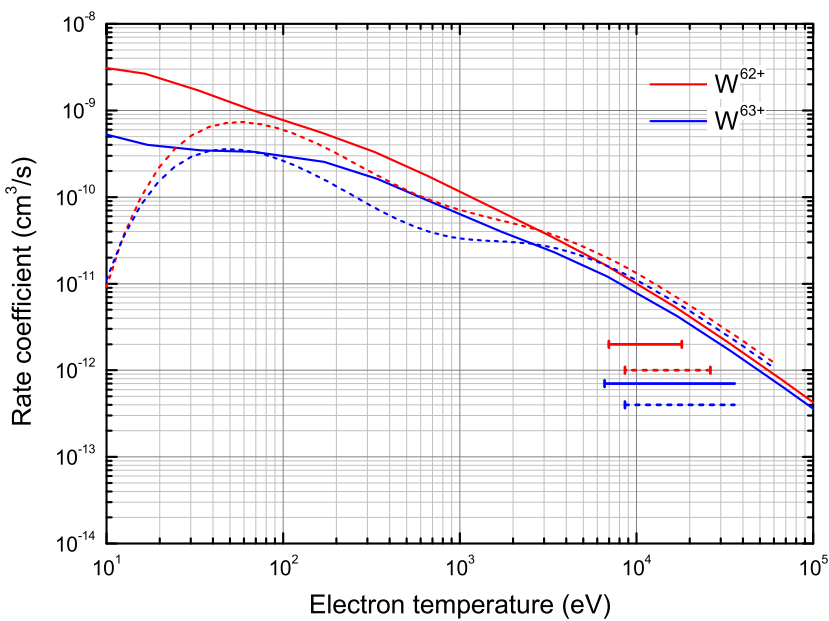

Fig. 8. Total DR rate coefficients for $\mathrm{W}^{q+}(q=62-63)$ of the $[\mathrm{Ne}] 3 \mathrm{~s}^{m}(m=2-1)$ ground level [58]. The solid and dotted horizontal bars represent the same as in Fig. 1. (For interpretation of the references to color in this figure legend, the reader is referred to the web version of this article.)

2 were included. For $\Delta n_{c}=0$, core excitations of $2 \mathrm{~s} \rightarrow 2 l$ and $2 \mathrm{p} \rightarrow 2 \mathrm{l}$ were included. For $\Delta n_{c}=1$, core excitations of $2 \mathrm{~s} \rightarrow 3 l$ and $2 \mathrm{p} \rightarrow 3 \mathrm{l}$. Lastly, for $\Delta n_{c}=2$, core excitations of $2 \mathrm{~s} \rightarrow 4 \mathrm{l}$ and $2 \mathrm{p} \rightarrow 4 l$ were included for $\mathrm{W}^{64+}$. Numerical convergence, and the $n l$ values included in the calculations, are as described in Sections 3.7 and 3.8. For $\mathrm{W}^{64+}$ the total rate coefficient computed using HULLAC is also available [61]. $\Delta n_{c}=1$ and 2 core excitations of $2 \mathrm{~s}$ and $2 \mathrm{p}$ electrons and $\Delta n_{c}=2$ core excitations of the $1 \mathrm{~s}$ electron from the ground level $[\mathrm{He}] 2 \mathrm{~s}^{2} 2 \mathrm{p}^{6}$ are included in the total rate coefficient. The captured electron $n l^{\prime}$ levels were explicitly calculated up to $n=13$ for the $\Delta n_{c}=1,2$ core excitations of $2 \mathrm{~s}$ and 2 p electrons and $l^{\prime} \leq 5$. DAC is negligible and was not included in the DR calculation. For the higher $n$ values an extrapolation using $1 / n^{3}$ scaling and constant law mixture considering slow convergence [56] was used [59]. For $1 s \rightarrow 3 l$ core excitation only the $3 l^{\prime}$ captured electron level was included in the total DR because the higher $n l^{\prime}$ level contribution is negligible. The total rate coefficient for $\mathrm{W}^{64+}$ computed using AUTOSTRUCTURE [58] agrees well with a HULLAC calculation [61]. The total rate coefficient for $\mathrm{W}^{64+}$ computed using a HFR Cowan calculation [62] is smaller than both the AUTOSTRUCTURE and HULLAC calculations over the entire temperature range, due to a smaller maximum $n(n \leq 7)$ value for which the captured electron level $n l^{\prime}$ was calculated explicitly. The colored lines in Fig. 9 represent the total rate coefficients for $\mathrm{W}^{q+}(q=64-69)$ computed using AUTOSTRUCTURE [58].

\subsection{0. $W^{q+}(q=70-71)$ of $[\mathrm{He}] 2 s^{m}$ ground configuration}

The total rate coefficient for $\mathrm{W}^{q+}(q=70-71)$ has been computed using AUTOSTRUCTURE [58]. $\Delta n_{c}=0,1,2$ core excitations were included for the $2 \mathrm{~s}^{m}$ total DR rate coefficients. For $\Delta n_{c}=0$, the $2 \mathrm{~s} \rightarrow 2 l$ core excitation was included. For $\Delta n_{c}=1$, the $2 \mathrm{~s} \rightarrow 3 \mathrm{l}$ core excitation was included. Finally, for $\Delta n_{c}=2$, the $2 \mathrm{~s} \rightarrow 4 \mathrm{l}$ core excitation was included. Numerical convergence, and $n l$ values calculated are as described in Sections 3.7-3.9. The red and blue lines in Fig. 10 represent the total rate coefficients for $\mathrm{W}^{70+}$ and $\mathrm{W}^{71+}$, respectively.

\subsection{1. $W^{q+}(q=72-73)$ of $1 s^{m}$ ground configuration}

The total rate coefficient for $\mathrm{W}^{q+}(q=72-73)$ has been computed using AUTOSTRUCTURE [58]. Core excitations of $\Delta n_{c}=1$ and 2 were included for these highly charged ions, i.e., the $1 s \rightarrow 2 l$

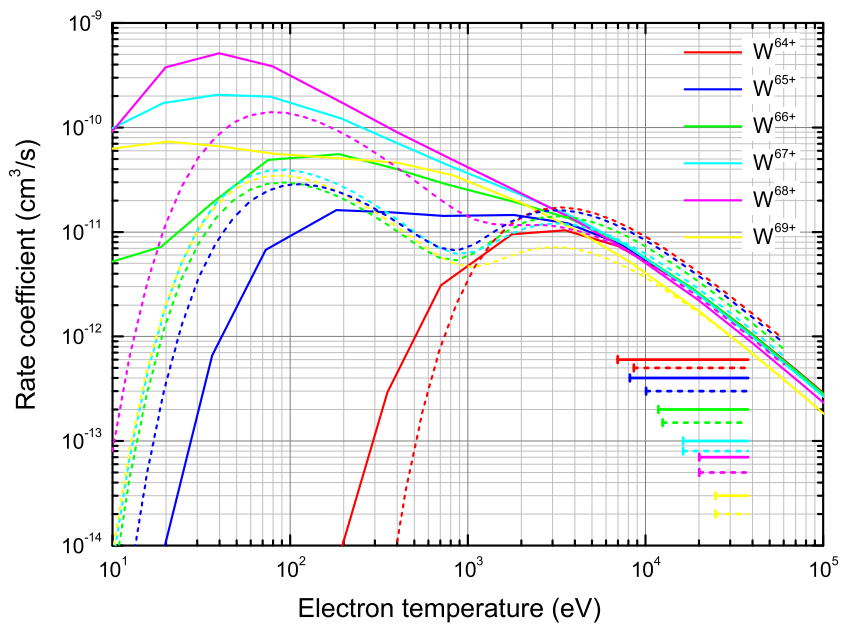

Fig. 9. Total DR rate coefficients for $\mathrm{W}^{q+}(q=64-69)$ of the $[\mathrm{He}] 2 \mathrm{~s}^{2} 2 \mathrm{p}^{m}(m=6-1)$ ground level [58]. The solid and dotted horizontal bars represent the same as in Fig. 1. (For interpretation of the references to color in this figure legend, the reader is referred to the web version of this article.)

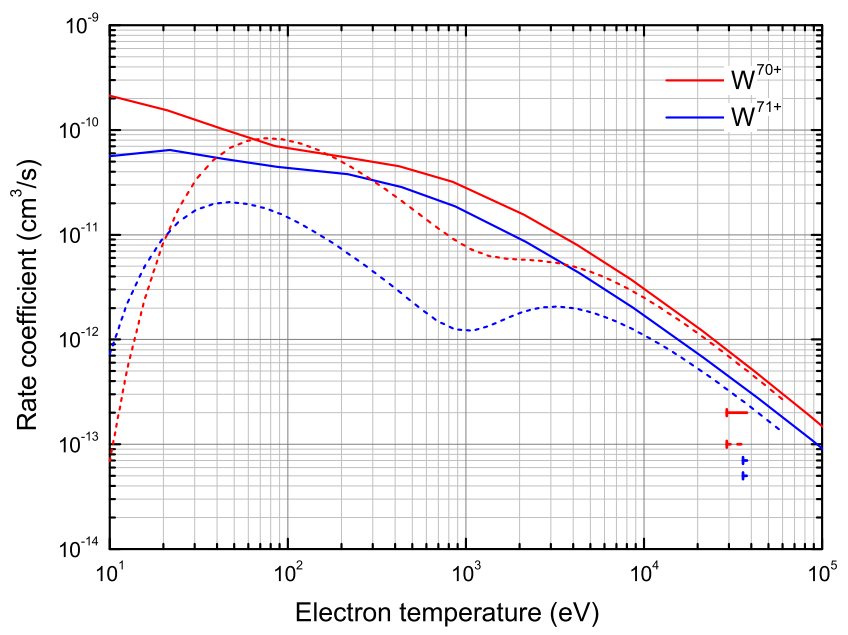

Fig. 10. Total DR rate coefficients for $\mathrm{W}^{q+}(q=70-71)$ of the $[\mathrm{He}] 2 \mathrm{~s}^{m}(m=2-1)$ ground level [58]. The solid and dotted horizontal bars represent the same as in Fig. 1.

and $1 s \rightarrow 3 l$ excitations were retained. Numerical convergence, and $n l$ values calculated are as described in Sections 3.7-3.10. The red and blue lines in Fig. 11 represent the total rate coefficients for $\mathrm{W}^{72+}$ and $\mathrm{W}^{73+}$, respectively.

\subsection{Fit parameters for the recommended rate coefficients}

We have fitted the recommended total DR rate coefficients for convenience in plasma modeling with the formula

$\alpha_{t o t}\left(T_{\mathrm{e}}\right)=\left(T_{\mathrm{e}}\right)^{-3 / 2} \sum_{i} c_{i} \exp \left(-\frac{E_{i}}{T_{\mathrm{e}}}\right)$.

Table 1 shows the list of the fit parameters. The fit is accurate to better than $3.0 \%$ over the whole temperature range displayed in the figures for the total rate coefficients for $\mathrm{W}$ ions in the above subsections except for $\mathrm{W}^{19+}, \mathrm{W}^{20+}, \mathrm{W}^{64+}, \mathrm{W}^{65+}, \mathrm{W}^{72+}$, and $\mathrm{W}^{73+}$. The numerical DR rate coefficients over the temperature ranges $1 \mathrm{eV}-17 \mathrm{keV}, 353.3 \mathrm{eV}-3533 \mathrm{keV}, 36.37 \mathrm{eV}-3637 \mathrm{keV}$, $4463 \mathrm{eV}-446.3 \mathrm{keV}$, and $4593 \mathrm{eV}-922.1 \mathrm{keV}$ are sampled in the fitting, for $\mathrm{W}^{20+}, \mathrm{W}^{64+}, \mathrm{W}^{65+}, \mathrm{W}^{72+}$, and $\mathrm{W}^{73+}$, respectively, and 


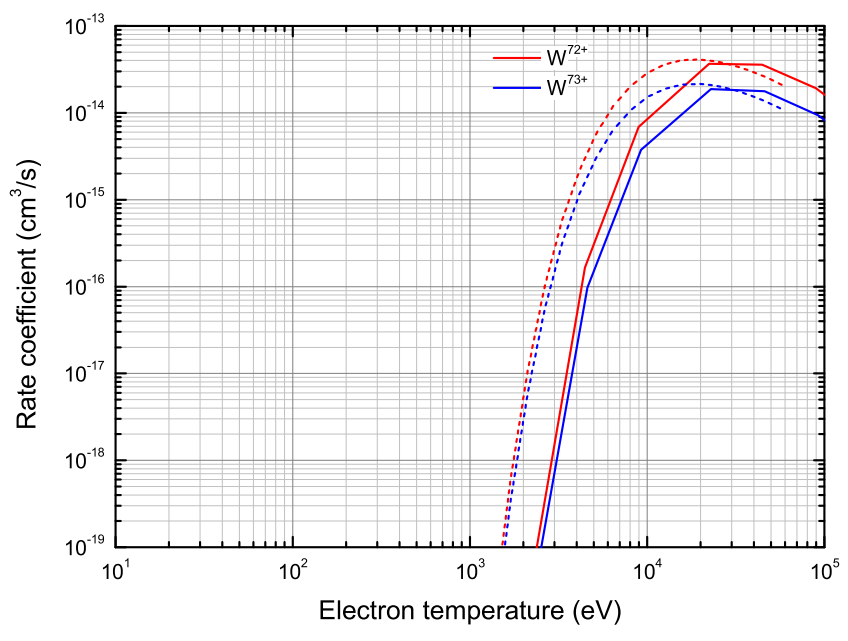

Fig. 11. Total DR rate coefficients for $\mathrm{W}^{q+}(q=72-73)$ of the $1 s^{m}(m=2-1)$ ground level [58].

the $3.0 \%$ fit accuracy corresponds to these temperature ranges. The total rate coefficient generated from the fit parameters listed in Table 1 is a smooth function without any deviation in the temperature range from $1 \mathrm{eV}$ to over $100 \mathrm{keV}$, except for some extremely highly-charged ions of $\mathrm{W}^{q+}(q \geq 61)$. The total rate coefficient from the fit parameters has a smooth form after $\sim 10 \mathrm{eV}$, $\sim 50 \mathrm{eV}, \sim 500 \mathrm{eV}, \sim 5000 \mathrm{eV}$, and $\sim 5000 \mathrm{eV}$, for $\mathrm{W}^{q+}(q=$ $61,63,64,66,68$, and 69$), \mathrm{W}^{65+}, \mathrm{W}^{72+}$, and $\mathrm{W}^{73+}$, respectively. It is noted that the fit parameters for $\mathrm{W}^{19+}$ come from [37] and they reproduce the experimentally derived rate coefficient with an accuracy better than $2 \%$ at temperatures $1-1000 \mathrm{eV}$.

\subsection{Fractional abundances}

Often, the plasma in a tokamak is optically thin, low-density, dust-free, in steady- or quasi-steady state. The effects of threebody recombination, radiation field, density, and charge exchange can be neglected and most ions have the majority of their population in the ground level under these conditions. The charge state distribution is determined by the balance of electron-impact ionization with recombination. This plasma state is typically called collisional ionization equilibrium. Since in collisional ionization equilibrium the population $N^{q}$ of ion $A^{q+}$ does not change in time, the fractional abundance $f^{q}$, defined by $f^{q}=N^{q} / N_{\text {tot }}$ for the total population $N_{\text {tot }}=\sum_{q=0}^{Z} N^{q}$ of atomic number $Z$ ions, satisfies the following Eq. [12]

$$
\begin{aligned}
N_{\text {tot }} \frac{d}{d t}\left[\begin{array}{c}
f^{0} \\
f^{1} \\
\vdots
\end{array}\right] & =N_{\text {tot }} n_{e}\left[\begin{array}{ccc}
-\alpha_{\mathrm{I}}^{0} & \alpha_{\mathrm{R}}^{1} & 0 \\
\alpha_{\mathrm{I}}^{0} & -\alpha_{\mathrm{R}}^{1}-\alpha_{\mathrm{I}}^{1} & \alpha_{\mathrm{R}}^{2} \\
0 & \alpha_{\mathrm{I}}^{1} & \ddots
\end{array}\right]\left[\begin{array}{c}
f^{0} \\
f^{1} \\
\vdots
\end{array}\right] \\
& =\left[\begin{array}{c}
0 \\
0 \\
\vdots
\end{array}\right],
\end{aligned}
$$

where $n_{e}$ is electron density, $\alpha_{\mathrm{I}}^{q}$ denotes the total ionization rate coefficient from charge state $q$ to $q+1$ and $\alpha_{\mathrm{R}}^{q}$ represent the total recombination rate coefficient from charge state $q$ to $q-1 . f^{q}$ should be normalized such that $\sum_{q=0}^{Z} f^{q}=1$.

The total ionization rate coefficients available on the ADAS database for all charge states of $\mathrm{W}$ come from CADW calculations [9], and are used for the fractional abundance calculation. The total recombination $(\mathrm{RR}+\mathrm{DR})$ rate coefficients in the ADAS database are replaced with our recommended total DR rate coefficients for ion stages available in the present recommended data set, except for $\mathrm{W}^{q+}(q=64-73)$, since recombination is due primarily to DR in the temperature range relevant to tokamak plasma for most ion stages. For $\mathrm{W}^{q+}(q=64-73) \mathrm{RR}$ can be comparable to DR or even the dominant contribution to the total recombination, as shown in [58]. The temperature range where the fractional abundance is over $1 \%$ is displayed with a horizontal bar for the calculated temperature range 1-37 $936 \mathrm{eV}$ in Figs. 1-10.

It is worth mentioning that the new recommended DR rate coefficients vary monotonically, while the previous ADAS DR rate coefficients exhibit a threshold at low temperatures as shown in Figs. 2-10. This behavior can be explained by the fact that the DR resonances of recombined ions are taken into account in the new recommended DR rate coefficients from ab-initio calculations and experiments explicitly, while the previous ADAS DR rate coefficients are based on the simple Burgess formula, which gives the DR rate coefficients through an extrapolation of excitation cross sections of recombining ion to energies slightly below the excitation threshold [5]. This approximation within the Burgess formula for high-energy resonances without description of low energy DR resonances, leads to a much lower DR rate and a much lower resulting $R R+D R$ rate coefficients than the present recommended DR rate coefficients at low temperatures. This modification in the recombination rate coefficient is the main reason for the change in fractional abundances of the $\mathrm{W}$ ions.

\section{Discussions}

\subsection{Resonance width at low energies: Chaotic mixing vs partitioned and damped approach}

Flambaum et al. [63] offer an alternative approach to explicit (and computationally intensive) calculations involving billions of autoionization and radiative rates as implemented within perturbative codes such as HULLAC, AUTOSTRUCTURE and FAC. For highly complex multi-electron systems, such as $\mathrm{W}^{20+}$, traditional approaches of including correlations via ever increasing configuration-interaction expansions cannot be applied to the extent necessary to obtain a converged theoretical result. Therefore, this results in traditional intermediate-coupling calculations having smaller resonance strengths compared to measured ones at low collision energies. Flambaum et al. adopt a statistical theory framework [63] to account for the apparent reduced recombination resonance at low energies. This theory provides a better description of the highly mixed dielectronic capture processes via a Breit-Wigner redistribution, which leads to a much better agreement with rates derived from merged-beam experiments. This theoretical idea has been used in recent papers by Spruck et al. [36], and implemented within the AUTOSTRUCTURE code.

\subsection{Collisional (density) effect on DR}

Electron-impact collisions, beyond the dielectronic capture process, can affect the total DR rate in several ways. As collisional processes compete with radiative decays, the modifications to the DR rates have an increasing effect with density (more rapid collisions) and a decreasing effect with temperature, or ionic charge (stronger radiative decays). At moderate densities, both collisions from the ground level as well as radiative decays from doublyexcited levels can populate metastable levels. This reduces the DR rate from the ground level, but can open new DR channels from these excited levels [64,65]. At even higher densities these levels are de-populated by collisions, but generally the population of excited levels increases.

The main influence of electron collisions on the DR rates is through the altering of the population of autoionizing levels. Three 
collisional processes play a role here: collisional transitions between autoionizing levels (sometimes referred to as collisional mixing), collisional stabilization to non-autoionizing levels, and collisional ionization from autoionizing levels. Collisional mixing starts to be effective at lower densities, especially for low- $n$ levels that contribute the most to the total DR rate. This re-distribution of level populations affects the total DR rate mostly by shifting ions from strongly autoionizing levels where capture occurs $\left(\bar{\sigma}^{\mathrm{DC}} \propto A^{a}\right.$ in Eq. (4)) to levels that favor more stabilization over autoionization. Hence, DR rates are enhanced. The other two effects act in opposite directions on the branching ratio, as collisional stabilization enhances recombination, while collisional ionization reduces it. The former dominates at lower levels, while the latter dominates at higher ones.

Although the density effect on DR was studied already by Burgess \& Summers in 1969 [66], very few works followed, obviously owing to the complexity of the problem. As a result, we are not able to provide definitive corrections to the recommended lowdensity DR rates under fusion plasma conditions. The following is only suggestive of the qualitative guidelines for such corrections. Collisional ionization of high- $n$ levels is probably the easiest to include. It should be possible to estimate for each ion some critical principal quantum number $n_{c}$, as a function of density and temperature, above which collisional ionization dominates, and the levels are effectively no longer bound. These high- $n$ levels can then be excluded from the DR calculations. However, the more important effect in fusion plasmas (lower densities) is likely that of collisional mixing, since lower- $n$ configurations have the dominant contribution to the DR rates. At the highest densities approaching local thermodynamic equilibrium (LTE), one may assume statistical populations. However in fusion plasma this is not a good approximation for most levels (except very high- $n$ ). The first attempt to properly model collisional mixing in the context of DR was done by Jacobs and co-workers $[67,68]$. The density effect on DR of closed-shell Ne-like ions was studied in Ref. [69], where Ne-like $\mathrm{W}^{64+}$ was also included. The density effect on the DR rates of $\mathrm{W}^{64+}$ was found to be negligible up to densities of $n_{e}>$ $10^{22} \mathrm{~cm}^{-3}$, so clearly irrelevant for fusion plasmas. However, it is expected that the effect on DR will be stronger for lower charge states, and in particular for open-shell ions. Consequently, the DR rates of these ions will suffer the most from the lack of densitydependent rates. We encourage researchers to carry out more case studies, in order to obtain a better idea of the importance of the collisional effect in the density regime of fusion plasmas.

\subsection{DR data generated in $C R$ modeling codes}

When studying high-density plasmas with CR modeling, the use of level-resolved or total DR rate coefficients is typically abandoned in favor of the autoionization levels being treated on an equal footing with the bound levels. In this way, the deviation of autoionization populations from their coronal values can be taken into account in a natural way, resulting in a more accurate charge state distribution and producing the appropriate limiting behavior, i.e. collision-dominated LTE. Additionally, satellite emission lines that originate from autoionization levels can be calculated in a straightforward manner. This CR approach is employed, for example, in the majority of code submissions to the series of Non-LTE Code Comparison Workshops [70-77], at which tungsten has been featured as a test case a number of times.

Despite this explicit treatment of autoionization levels, total (effective) DR rate coefficients can be obtained after the entire set of level populations has been calculated for a given temperature and density by summing over the autoionization populations in a manner similar to that used in the branching-ratio method. As an illustrative example, we present in Fig. 12 the total DR rate

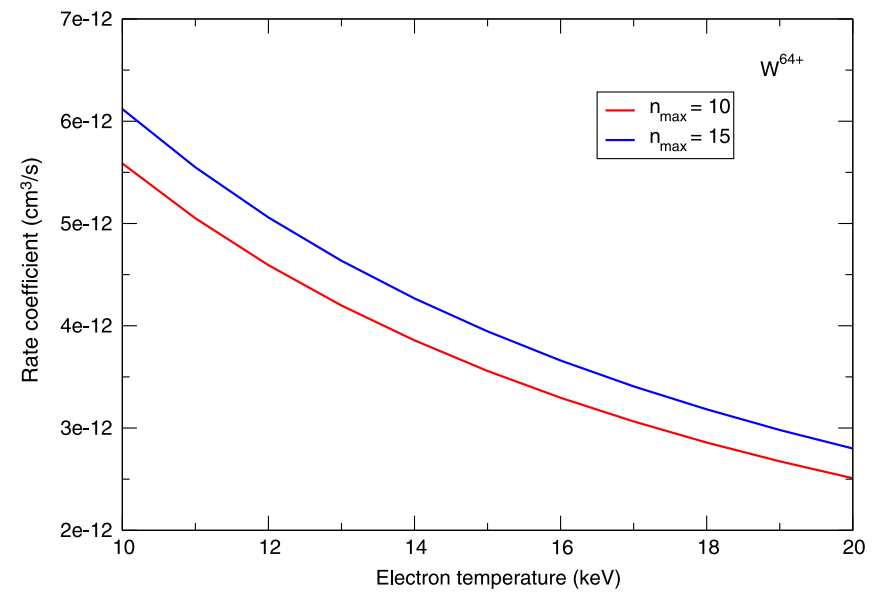

Fig. 12. Total DR rate coefficient for $\mathrm{W}^{64+}$ calculated at an electron density of $n_{e}=10^{14} \mathrm{~cm}^{-3}$. The lower red curve represents a model with $n_{\max }=10$ and the higher blue curve represents an $n_{\max }=15$ model.

coefficient for $\mathrm{W}^{64+}$ at a typical tokamak electron density of $n_{e}=$ $10^{14} \mathrm{~cm}^{-3}$. These data were calculated with the semi-relativistic option of the Los Alamos suite of codes [78] for two different models: one with maximum principal quantum $n_{\max }=10$ and a larger model with $n_{\max }=15$. Results are presented for the limited temperature range of $10-20 \mathrm{keV}$, as it can be numerically challenging to solve the CR equations for ion stages that have a very small fractional population for a given set of plasma conditions.

Increasing the atomic physics model from $n_{\max }=10$ to 15 produces an increase in the rate coefficients of $\sim 10 \%$ over this temperature range. The $n_{\max }=15$ data are comparable to, or slightly larger than, the corresponding $\mathrm{W}^{64+}$ zero-density data displayed in Fig. 9, suggesting that density effects are not too significant in this case, which agrees with the discussion in the previous section. Similar, reasonable agreement is observed when comparing other ion stages, although the CR-modeling data is sometimes lower than the branching-ratio results by as much as $20 \%$ when moving away from the closed-shell, Ne-like case discussed above. These discrepancies could be due to density effects or to the fact that the recommended data include contributions from very high-lying autoionization levels via the $1 / n^{3}$ scaling law.

\section{Summary and outlook}

We have compiled recent state-of-the art theoretical and experimental DR data for the iso-nuclear tungsten sequence. The calculated data have been assessed by examining the included resonance channels and the extrapolation methods for high-energy $\mathrm{DR}$, and by comparing it with the data generated in CR modeling codes and available experiments. A set of recommended DR data for tungsten ionization stages has been obtained and presented together with the previous ADAS DR recombination data (obtained through a simple semi-empirical formula based on the Burgess general formula). The charge state distribution for iso-nuclear tungsten in collisional ionization equilibrium has been calculated using the new recommended DR data instead of the ADAS data for available ion stages. The $\mathrm{W}$ fractional abundances change significantly when the new recommended DR data set is used compared to when the previous ADAS recombination set is used. This change in the fractional abundance is mainly due to the large enhancement of the new recommended DR data set at low electron energies, below the peak abundance region, compared with the previous ADAS recombination data. The enhancement leads to a shift of the peak abundance electron energies towards a lower value and a 
large difference in the peak abundance. This demonstrates that the accuracy of DR data at low temperatures, where atomic physics plays an important role, is crucial for fusion plasma modeling and additional $a b$-initio calculations (and experiments) for ion stages not yet examined would be highly beneficial. Also, we have discussed more sophisticated treatments of calculations of the DR rates, such as through statistical chaotic mixing of resonance states near the threshold energy, and population of excited levels and collisional transitions (so called mixing) between resonance levels in a high electron density plasma.

For impurity transport modeling in fusion plasmas isonuclear sets of data are required. A systematic effort, "the tungsten project", announced in [58] will apply AUTOSTRUCTURE to calculate dielectronic and radiative recombination for all ionization stages of tungsten. The ionization data of [9] will be used with a modest revision taking into account higher $\mathrm{nl}$ contributions [79]. A revision of the radiated power is also underway to complete the set of data required for modeling. This review has highlighted the importance of benchmarking such systematic efforts against independent calculations and experiment.

\section{Acknowledgments}

This work was carried out at an IAEA consultants meeting on tungsten atomic data. D.-H. Kwon and W. Lee were supported by the Korean Ministry of Science, ICT, and Future Planning. E. Behar received funding from the European Union's Horizon 2020 research and innovation program under the Marie Sklodowska-Curie grant agreement no. 655324. Yu. Ralchenko is acknowledged for useful discussions concerning the use of CR modeling to generate effective rate coefficients.

\section{References}

[1] J. Roth, et al., J. Nucl. Mater. 1 (2009) 390.

[2] R.V. Jensen, et al., Nucl. Fusion 17 (1977) 118.

[3] T. Pütterich, et al., Nucl. Fusion 50 (2010) 025012.

[4] D.E. Post, et al., At. Data Nucl. Data Tables 20 (1977) 397.

[5] A. Burgess, Astrophys. J. 141 (1965) 1588; Astrophys. J. 139 (1964) 776.

[6] R.A. Hulse, Fusion Sci. Technol. 3 (1983) 259.

[7] K. Asmussen, et al., Nucl. Fusion 38 (1998) 967.

[8] T. Pütterich, et al., Plasma Phys. Control. Fusion 50 (2008) 085016.

[9] S.D. Loch, et al., Phys. Rev. A 72 (2005) 052716.

[10] Atomic Data and Analysis Structure (ADAS), http://open.adas.ac.uk.

[11] http://open.adas.ac.uk/detail/adf11/acd50/acd50_w.dat.

[12] P. Bryans, et al., Astrophys. J. Supp. Ser. 167 (2006) 343.

[13] Y. Hahn, K.J. LaGattuta, Phys. Rep. 166 (1988) 195.

[14] S.N. Nahar, A.K. Pradhan, Astrophys. J. 397 (1992) 729.

[15] S.N. Nahar, A.K. Pradhan, Astrophys. J. 549 (2001) L265-L268.

[16] V.L. Jacobs, J. Cooper, S.L. Haan, Phys. Rev. A 36 (1987) 1093.

[17] E. Behar, V.L. Jacobs, J. Oreg, A. Bar-Shalom, S.L. Haan, Phys. Rev. A 69 (2004) 022704.

[18] E. Behar, et al., Phys. Rev. A 52 (1995) 3770

[19] B.W. Shore, Astrophys. J. 158 (1969) 1205.

[20] C.P. Ballance, S.D. Loch, M.S. Pindzola, D.G. Griffin, J. Phys. B 43 (2010) 205201.

[21] K.A. Berrington, P.G. Burke, K. Butler, M.J. Seaton, P.J. Storey, K.T. Taylor, Y. Yan, J Phys. B: At. Mol. Phys. 20 (1987) 6379.

[22] D.C. Griffin, M.S. Pindzola, C.P. Ballance, J. Colgan, Phys. Rev. A 79 (2009) 023413.

[23] R.D. Cowan, The Theory of Atomic Structure and Spectra, University of California Press, Berkeley, 1981.

[24] N.R. Badnell, Comput. Phys. Comm. 182 (2011) 1528.

[25] A. Bar-Shalom, M. Klapisch, J. Oreg, J. Quant. Spectrosc. Radiat. Transfer 71 (2001) 169.
[26] M.F. Gu, Can. J. Phys. 86 (2008) 675.

[27] D.C. Griffin, M.S. Pindzola, C. Bottcher, Phys. Rev. A 31 (1985) 568.

[28] C.P. Ballance, D.C. Griffin, J. Phys. B 39 (2006) 3617.

[29] C.P. Ballance, et al., J. Phys. B 43 (2010) 205201.

[30] J. Colgan, C.J. Fontes, H.L. Zhang, J. Abdallah Jr., Atoms 3 (2015) 76.

[31] C.J. Fontes, J. Colgan, J. Abdallah Jr., Modern Methods in Collisional-Radiative Modeling of Plasmas, Springer, New York, 2016.

[32] U.I. Safronova, A.S. Safronova, P. Beiersdorfer, J. Phys. B 45 (2012) 085001.

[33] U.I. Safronova, A.S. Safronova, Phys. Rev. A 85 (2012) 032507.

[34] M.S. Safronova, W.R. Johnson, U.I. Safronova, Phys. Rev. A 53 (1996) 4036.

[35] A. Müller, Atoms 3 (2015) 120.

[36] K. Spruck, et al., Phys. Rev. A 90 (2014) 032715.

[37] N.R. Badnell, et al., Phys. Rev. A 93 (2016) 052703.

[38] S. Schippers, et al., Phys. Rev. A 83 (2011) 012711.

[39] N.R. Badnell, et al., Phys. Rev. A 85 (2012) 052716.

[40] H.K. Chung, et al., High Energy Density Phys. 1 (2005) 3.

[41] S. Preval, private communication.

[42] B.W. Li, et al., Phys. Rev. A 85 (2012) 052706.

[43] B.W. Li, et al., J. Phys. B 49 (2016) 155201.

[44] U.I. Safronova, et al., J. Phys. B 44 (2011) 035005.

[45] Z. Wu, et al., Eur. Phys. J. D 69 (2015) 140.

[46] F.C. Meng, et al., J. Quant. Spectrosc. Radiat. Transfer 109 (2008) 2000.

[47] Z. Wu, et al., Atoms 3 (2015) 474.

[48] M.J. Li, et al., Plasma Sci. Technol. 16 (2016) 182.

[49] M.J. Li, et al., J. Phys. Conf. Ser. 488 (2014) 062022.

[50] D.-H. Kwon, W. Lee, J. Quant. Spectrosc. Radiat. Transfer 179 (2016) 98.

[51] D.-H. Kwon, W. Lee, J. Quant. Spectrosc. Radiat. Transfer 170 (2016) 182.

[52] T. Nakano, Experimental evaluation of $\mathrm{W}^{44+}$ ionization and $\mathrm{W}^{45+}$ recombination cross-sections, ICAMDATA, Gunsan, Korea, 2016.

[53] E. Behar, et al., J. Quant. Spectrosc. Radiat. Transfer 58 (1997) 449.

[54] U.I. Safronova, A.S. Safronova, P. Beiersdorfer, Phys. Rev. A 91 (2015) 062507.

[55] E. Behar, P. Mandelbaum, J.L. Schwob, Eur. Phys. J. D 7 (1999) 157.

[56] E. Behar, et al., Phys. Rev. A 54 (1996) 3070.

[57] U.I. Safronova, A.S. Safronova, P. Beiersdorfer, Phys. Rev. A 86 (2012) 042510.

[58] S.P. Preval, N.R. Badnell, M.G. O’Mullane, Phys. Rev. A 93 (2016) 042703.

[59] A. Peleg, et al., Phys. Rev. A 57 (1998) 3493.

[60] U.I. Safronova, A.S. Safronova, P. Beiersdorfer, J. Phys. B 42 (2009) 165010.

[61] E. Behar, P. Mandelbaum, J.L. Schwob, Phys. Rev. A 59 (1999) 2787.

[62] U.I. Safronova, A.S. Safronova, P. Beiersdorfer, At. Data Nucl. Data Tables 95 (2009) 751.

[63] V.V. Flambaum, A.A. Gribakina, G.F. Gribakin, C. Harabati, Phys. Rev. A 66 (2002) 012713.

[64] N.R. Badnell, et al., Astron. Astrophys. 406 (2003) 1151.

[65] H.P. Summers, et al., Plasma Phys. Control. Fusion 48 (2006) 263.

[66] A. Burgess, H.P. Summers, Astrophys. J. 157 (1969) 1007.

[67] V.L. Jacobs, J. Davis, Phys. Rev. A 18 (1978) 697.

[68] V.L. Jacobs, M. Blaha, Phys. Rev. A 21 (1980) 125.

[69] E. Behar, R. Doron, P. Mandelbaum, J.L. Schwob, Phys. Rev. A 61 (2000) 062708.

[70] R.W. Lee, J.K. Nash, Y. Ralchenko, J. Quant. Spectrosc. Radiat. Transfer 58 (1997) 737.

[71] C. Bowen, A. Decoster, C.J. Fontes, O. Peyrusse, Yu. Ralchenko, J. Quant. Spectrosc. Radiat. Transfer 81 (2003) 71.

[72] C. Bowen, R.W. Lee, Yu. Ralchenko, J. Quant. Spec. Rad. Trans. 99 (2006) 102.

[73] J.G. Rubiano, R. Florido, C. Bowen, R.W. Lee, Yu Ralchenko, High Energy Density Phys. 3 (2007) 225.

[74] C.J. Fontes, J. Abdallah Jr., C. Bowen, R.W. Lee, Yu. Ralchenko, High Energy Density Phys. 5 (2009) 15.

[75] The NLTE-6 Code Comparison Workshop, unpublished, http://nlte.nist.gov/ NLTE6/.

[76] H.-K. Chung, C. Bowen, C.J. Fontes, S.B. Hansen, Yu Ralchenko, High Energy Density Phys. 9 (2013) 645.

[77] The NLTE-8 Code Comparison Workshop, unpublished, http://nlte.nist.gov/ NLTE8/.

[78] C.J. Fontes, H.L. Zhang, J. Abdallah Jr., R.E.H. Clark, D.P. Kilcrease, J. Colgan, R.T. Cunningham, P. Hakel, N.H. Magee, M.E. Sherrill, J. Phys. B 48 (2015) 144014.

[79] V. Jonauskas, et al., Phys. Rev. A 191 (2015) 012715. 


\section{Explanation of Tables}

Table 1.

Fit parameters for the recommended total DR Maxwellian rate coefficients of $W$ ions.

Ion

Charge state of W

C

Fit parameters for the formula of Eq. (8) given in the unit $\left(10^{-10} \mathrm{~cm}^{3} \mathrm{~s}^{-1} \mathrm{eV}^{3 / 2}\right)$

Fit parameters for the formula of Eq. (8) given in the unit $(\mathrm{eV})$ 
Table 1

Fit parameters for the recommended total DR Maxwellian rate coefficients of $\mathrm{W}$ ions.

\begin{tabular}{|c|c|c|c|c|c|c|c|c|}
\hline Ion & $c_{1}$ & $c_{2}$ & $c_{3}$ & $c_{4}$ & $c_{5}$ & $c_{6}$ & $c_{7}$ & $c_{8}$ \\
\hline $\mathrm{W}^{5+}$ & $1.522 \mathrm{E}+0$ & $1.498 \mathrm{E}+0$ & $4.634 \mathrm{E}+0$ & $1.935 \mathrm{E}+3$ & $2.284 \mathrm{E}+1$ & $1.609 \mathrm{E}+2$ & $4.193 \mathrm{E}+2$ & $1.066 \mathrm{E}+3$ \\
\hline $\mathrm{W}^{6+}$ & $3.621 \mathrm{E}-1$ & $2.078 \mathrm{E}+0$ & $1.826 \mathrm{E}+0$ & $1.395 \mathrm{E}+1$ & $1.025 \mathrm{E}+2$ & $4.998 \mathrm{E}+2$ & $1.812 \mathrm{E}+3$ & $2.667 \mathrm{E}+3$ \\
\hline $\mathrm{W}^{18+}$ & $1.091 \mathrm{E}+4$ & $1.580 \mathrm{E}+3$ & $6.676 \mathrm{E}+3$ & $1.656 \mathrm{E}+3$ & $7.083 \mathrm{E}+3$ & $4.845 \mathrm{E}+2$ & $5.379 \mathrm{E}+3$ & $6.347 \mathrm{E}+2$ \\
\hline $\mathrm{W}^{19+}$ & $6.284 \mathrm{E}+2$ & $2.272 \mathrm{E}+3$ & $5.463 \mathrm{E}+3$ & $1.186 \mathrm{E}+4$ & $2.032 \mathrm{E}+4$ & $3.269 \mathrm{E}+4$ & $2.092 \mathrm{E}+4$ & \\
\hline $\mathrm{W}^{20+}$ & $1.115 \mathrm{E}+4$ & $1.066 \mathrm{E}+3$ & $4.370 \mathrm{E}+3$ & $3.895 \mathrm{E}+3$ & $4.256 \mathrm{E}+3$ & $2.059 \mathrm{E}+4$ & $1.731 \mathrm{E}+3$ & $4.225 \mathrm{E}-2$ \\
\hline $\mathrm{W}^{27+}$ & $1.908 \mathrm{E}+1$ & $3.980 \mathrm{E}+2$ & $2.491 \mathrm{E}+1$ & $1.230 \mathrm{E}+4$ & $9.574 \mathrm{E}+2$ & $1.549 \mathrm{E}+4$ & $3.066 \mathrm{E}+3$ & $1.231 \mathrm{E}+2$ \\
\hline $\mathrm{W}^{28+}$ & $5.139 \mathrm{E}+0$ & $6.893 \mathrm{E}+2$ & $5.023 \mathrm{E}+1$ & $2.187 \mathrm{E}+2$ & $3.224 \mathrm{E}+3$ & $1.425 \mathrm{E}+4$ & $6.580 \mathrm{E}+4$ & $5.043 E+4$ \\
\hline $\mathrm{W}^{29+}$ & $1.754 \mathrm{E}+1$ & $2.428 \mathrm{E}+2$ & $8.514 \mathrm{E}+1$ & $1.109 \mathrm{E}+4$ & $8.726 \mathrm{E}+2$ & $6.650 \mathrm{E}+4$ & $3.293 \mathrm{E}+3$ & $3.191 \mathrm{E}+4$ \\
\hline $\mathrm{W}^{35+}$ & $4.546 \mathrm{E}+3$ & $3.111 \mathrm{E}+4$ & $1.296 \mathrm{E}+4$ & $3.099 \mathrm{E}+4$ & $1.868 \mathrm{E}+4$ & $2.849 \mathrm{E}+4$ & $4.744 \mathrm{E}+0$ & $2.783 \mathrm{E}+4$ \\
\hline $\mathrm{W}^{37+}$ & $1.944 \mathrm{E}+5$ & $3.572 \mathrm{E}+3$ & $1.686 \mathrm{E}+5$ & $5.832 \mathrm{E}+4$ & $1.059 \mathrm{E}+5$ & $7.537 \mathrm{E}+2$ & $1.309 \mathrm{E}+4$ & $1.924 \mathrm{E}+3$ \\
\hline $\mathrm{W}^{38+}$ & $1.930 \mathrm{E}+5$ & $2.253 \mathrm{E}+3$ & $1.352 \mathrm{E}+5$ & $5.240 \mathrm{E}+2$ & $6.862 \mathrm{E}+4$ & $7.140 \mathrm{E}+3$ & $2.089 \mathrm{E}+1$ & $2.874 \mathrm{E}+4$ \\
\hline $\mathrm{W}^{39+}$ & $6.426 \mathrm{E}+4$ & $1.983 \mathrm{E}+3$ & $2.009 \mathrm{E}+5$ & $1.395 \mathrm{E}+5$ & $3.093 \mathrm{E}+4$ & $5.543 \mathrm{E}+3$ & $8.941 \mathrm{E}+1$ & $7.002 \mathrm{E}+2$ \\
\hline $\mathrm{W}^{41+}$ & $3.357 \mathrm{E}+3$ & $3.300 \mathrm{E}+4$ & $1.244 \mathrm{E}+4$ & $6.968 \mathrm{E}-5$ & $1.804 \mathrm{E}+5$ & $1.098 \mathrm{E}+5$ & $1.030 \mathrm{E}+3$ & $3.689 \mathrm{E}+2$ \\
\hline$W^{42+}$ & $2.179 \mathrm{E}+5$ & $7.182 \mathrm{E}+2$ & $1.134 \mathrm{E}+5$ & $1.454 \mathrm{E}+4$ & $3.734 \mathrm{E}+4$ & $5.830 \mathrm{E}+3$ & $1.503 \mathrm{E}+3$ & $3.521 \mathrm{E}+1$ \\
\hline $\mathrm{W}^{43+}$ & $2.437 \mathrm{E}+5$ & $7.246 \mathrm{E}+2$ & $5.210 \mathrm{E}+4$ & $2.601 \mathrm{E}+3$ & $2.108 \mathrm{E}+4$ & $1.343 \mathrm{E}+5$ & $1.753 \mathrm{E}+0$ & $3.896 \mathrm{E}+3$ \\
\hline$W^{44+}$ & $9.745 \mathrm{E}+4$ & $3.223 \mathrm{E}+3$ & $3.215 \mathrm{E}+4$ & $3.294 \mathrm{E}+0$ & $1.639 \mathrm{E}+5$ & $1.847 \mathrm{E}+4$ & $4.804 \mathrm{E}+2$ & $1.673 \mathrm{E}+3$ \\
\hline$W^{45+}$ & $4.167 \mathrm{E}+1$ & $5.403 \mathrm{E}+2$ & $2.968 \mathrm{E}+4$ & $2.030 \mathrm{E}+3$ & $1.605 \mathrm{E}+5$ & $4.945 \mathrm{E}+3$ & $1.153 \mathrm{E}+2$ & $6.013 E+4$ \\
\hline $\mathrm{W}^{46+}$ & $8.346 \mathrm{E}-1$ & $2.554 \mathrm{E}+0$ & $-3.089 \mathrm{E}-1$ & $3.031 \mathrm{E}+4$ & $1.488 \mathrm{E}+5$ & $5.371 \mathrm{E}+3$ & $-6.109 \mathrm{E}+3$ & $1.722 \mathrm{E}+2$ \\
\hline $\mathrm{W}^{47+}$ & $2.459 \mathrm{E}+1$ & $3.331 \mathrm{E}+2$ & $1.386 \mathrm{E}+0$ & $1.275 \mathrm{E}+4$ & $7.665 \mathrm{E}+1$ & $2.198 \mathrm{E}+3$ & $1.833 \mathrm{E}+5$ & $3.548 \mathrm{E}+4$ \\
\hline $\mathrm{W}^{56+}$ & $4.625 \mathrm{E}+4$ & $2.667 \mathrm{E}+3$ & $4.998 \mathrm{E}+4$ & $7.314 \mathrm{E}+4$ & $1.279 \mathrm{E}+4$ & $8.424 \mathrm{E}+0$ & $4.159 \mathrm{E}+2$ & $3.277 \mathrm{E}+2$ \\
\hline $\mathrm{W}^{57+}$ & $5.046 \mathrm{E}+4$ & $2.246 \mathrm{E}+3$ & $5.372 \mathrm{E}+4$ & $7.704 \mathrm{E}+2$ & $1.881 \mathrm{E}+4$ & $1.161 \mathrm{E}+3$ & $7.425 \mathrm{E}+4$ & $7.613 E+2$ \\
\hline$W^{58+}$ & $7.076 \mathrm{E}+4$ & $1.220 \mathrm{E}+4$ & $5.579 \mathrm{E}+4$ & $2.701 \mathrm{E}+3$ & $2.855 \mathrm{E}+4$ & $2.808 \mathrm{E}+4$ & $3.345 \mathrm{E}+2$ & $2.222 \mathrm{E}+2$ \\
\hline $\mathrm{W}^{59+}$ & $5.883 \mathrm{E}+4$ & $1.031 \mathrm{E}+3$ & $5.389 \mathrm{E}+4$ & $1.555 \mathrm{E}+4$ & $5.911 \mathrm{E}+4$ & $1.707 \mathrm{E}+3$ & $1.804 \mathrm{E}+1$ & $6.090 \mathrm{E}+2$ \\
\hline $\mathrm{W}^{60+}$ & $5.916 \mathrm{E}+4$ & $6.358 \mathrm{E}+3$ & $4.545 \mathrm{E}+4$ & $5.917 \mathrm{E}+2$ & $1.643 \mathrm{E}+4$ & $5.545 \mathrm{E}+2$ & $2.743 \mathrm{E}+2$ & $4.436 \mathrm{E}+4$ \\
\hline $\mathrm{W}^{61+}$ & $6.268 \mathrm{E}+4$ & $2.426 \mathrm{E}+3$ & $4.351 \mathrm{E}+4$ & $4.150 \mathrm{E}+4$ & $1.090 \mathrm{E}+4$ & $-5.567 \mathrm{E}+0$ & $2.608 \mathrm{E}+1$ & $3.098 \mathrm{E}+2$ \\
\hline $\mathrm{W}^{62+}$ & $4.629 \mathrm{E}+4$ & $1.662 \mathrm{E}+4$ & $4.611 \mathrm{E}+4$ & $2.810 \mathrm{E}+3$ & $2.495 \mathrm{E}+4$ & $5.204 \mathrm{E}+2$ & $5.213 \mathrm{E}+2$ & $2.383 E+3$ \\
\hline$W^{63+}$ & $2.967 \mathrm{E}+4$ & $1.624 \mathrm{E}+2$ & $1.465 \mathrm{E}+4$ & $3.169 \mathrm{E}+2$ & $5.546 \mathrm{E}+3$ & $7.138 \mathrm{E}+1$ & $9.708 \mathrm{E}+0$ & $6.869 \mathrm{E}+4$ \\
\hline $\mathrm{W}^{64+}$ & $4.491 \mathrm{E}+3$ & $2.106 \mathrm{E}+4$ & $4.582 \mathrm{E}+3$ & $3.703 \mathrm{E}+3$ & $4.708 \mathrm{E}+3$ & $1.097 \mathrm{E}+4$ & $6.418 \mathrm{E}+3$ & $4.206 \mathrm{E}+4$ \\
\hline $\mathrm{W}^{65+}$ & $-7.105 \mathrm{E}-2$ & $2.098 \mathrm{E}+0$ & $-1.830 \mathrm{E}-1$ & $3.007 \mathrm{E}+4$ & $-2.277 \mathrm{E}-1$ & $5.941 \mathrm{E}+4$ & $1.665 \mathrm{E}+3$ & $3.598 \mathrm{E}+3$ \\
\hline $\mathrm{W}^{66+}$ & $4.533 \mathrm{E}+4$ & $2.400 \mathrm{E}+0$ & $3.553 \mathrm{E}+4$ & $3.384 \mathrm{E}+3$ & $-1.293 \mathrm{E}+0$ & $1.624 \mathrm{E}+1$ & $6.857 \mathrm{E}+2$ & $9.499 \mathrm{E}+3$ \\
\hline$W^{67+}$ & $5.380 \mathrm{E}+4$ & $1.780 \mathrm{E}+0$ & $-6.263 \mathrm{E}+0$ & $2.497 \mathrm{E}+4$ & $2.650 \mathrm{E}+1$ & $6.196 \mathrm{E}+3$ & $5.962 \mathrm{E}+2$ & $3.908 \mathrm{E}+3$ \\
\hline $\mathrm{W}^{68+}$ & $5.635 \mathrm{E}+3$ & $1.998 \mathrm{E}+0$ & $5.455 \mathrm{E}+4$ & $-2.401 \mathrm{E}-3$ & $-6.597 \mathrm{E}-1$ & $1.682 \mathrm{E}+4$ & $1.144 \mathrm{E}+2$ & $-3.541 \mathrm{E}+0$ \\
\hline$W^{69+}$ & $3.096 \mathrm{E}+4$ & $2.042 \mathrm{E}+0$ & $-2.221 \mathrm{E}-1$ & $9.759 \mathrm{E}+3$ & $1.901 \mathrm{E}+1$ & $1.944 \mathrm{E}+4$ & $1.592 \mathrm{E}+2$ & $1.051 \mathrm{E}+3$ \\
\hline $\mathrm{W}^{70+}$ & $1.092 \mathrm{E}+4$ & $3.796 \mathrm{E}+1$ & $1.874 \mathrm{E}+4$ & $3.548 \mathrm{E}+1$ & $2.099 \mathrm{E}+4$ & $3.234 \mathrm{E}+1$ & $1.094 \mathrm{E}+3$ & $2.185 E+2$ \\
\hline $\mathrm{W}^{71+}$ & $8.274 \mathrm{E}+2$ & $2.211 \mathrm{E}+0$ & $4.250 \mathrm{E}+0$ & $1.094 \mathrm{E}+4$ & $9.242 \mathrm{E}+3$ & $7.867 \mathrm{E}+3$ & $4.527 \mathrm{E}+3$ & $1.713 \mathrm{E}+2$ \\
\hline$W^{72+}$ & $1.618 \mathrm{E}+3$ & $-9.190 \mathrm{E}+3$ & $1.609 \mathrm{E}+3$ & $1.568 \mathrm{E}+3$ & $1.598 \mathrm{E}+3$ & $1.528 \mathrm{E}+3$ & $6.006 \mathrm{E}+0$ & $1.462 \mathrm{E}+3$ \\
\hline$W^{73+}$ & $-3.187 E+3$ & $-1.626 \mathrm{E}+0$ & $-1.876 \mathrm{E}+3$ & $1.895 \mathrm{E}+3$ & $-1.567 \mathrm{E}+3$ & $2.021 \mathrm{E}+3$ & $8.618 \mathrm{E}+1$ & $2.328 \mathrm{E}+3$ \\
\hline & $E_{1}$ & $E_{2}$ & $E_{3}$ & $E_{4}$ & $E_{5}$ & $E_{6}$ & $E_{7}$ & $E_{8}$ \\
\hline $\mathrm{w}^{5+}$ & $3.231 \mathrm{E}-1$ & $7.116 \mathrm{E}-1$ & $2.061 \mathrm{E}+0$ & $8.237 \mathrm{E}+1$ & $5.941 \mathrm{E}+0$ & $1.750 \mathrm{E}+1$ & $3.547 \mathrm{E}+1$ & $5.425 \mathrm{E}+1$ \\
\hline $\mathrm{W}^{6+}$ & $5.417 \mathrm{E}-1$ & $1.818 \mathrm{E}+0$ & $1.819 \mathrm{E}+0$ & $5.560 \mathrm{E}+0$ & $9.324 \mathrm{E}+0$ & $2.078 \mathrm{E}+1$ & $7.665 \mathrm{E}+1$ & $3.842 \mathrm{E}+1$ \\
\hline $\mathrm{W}^{18+}$ & $1.171 \mathrm{E}+2$ & $4.059 \mathrm{E}+0$ & $1.155 \mathrm{E}+1$ & $4.060 \mathrm{E}+0$ & $3.435 \mathrm{E}+1$ & $1.560 \mathrm{E}+0$ & $9.608 \mathrm{E}+2$ & $6.533 \mathrm{E}-1$ \\
\hline $\mathrm{W}^{19+}$ & $5.516 \mathrm{E}-1$ & $2.865 \mathrm{E}+0$ & $9.073 \mathrm{E}+0$ & $2.355 \mathrm{E}+1$ & $5.983 \mathrm{E}+1$ & $1.373 \mathrm{E}+2$ & $2.394 \mathrm{E}+2$ & \\
\hline $\mathrm{W}^{20+}$ & $5.190 \mathrm{E}+1$ & $1.423 \mathrm{E}+0$ & $1.608 \mathrm{E}+1$ & $1.608 \mathrm{E}+1$ & $4.369 \mathrm{E}+0$ & $3.413 \mathrm{E}+2$ & $4.915 \mathrm{E}-1$ & $1.929 \mathrm{E}-1$ \\
\hline $\mathrm{W}^{27+}$ & $6.916 \mathrm{E}-2$ & $2.571 \mathrm{E}+0$ & $2.048 \mathrm{E}-1$ & $1.037 \mathrm{E}+2$ & $8.292 \mathrm{E}+0$ & $2.833 \mathrm{E}+2$ & $3.319 \mathrm{E}+1$ & $7.250 \mathrm{E}-1$ \\
\hline $\mathrm{W}^{28+}$ & $9.196 \mathrm{E}-2$ & $6.868 \mathrm{E}+0$ & $6.952 \mathrm{E}-1$ & $2.179 \mathrm{E}+0$ & $2.242 \mathrm{E}+1$ & $5.884 \mathrm{E}+1$ & $1.876 \mathrm{E}+2$ & $4.721 \mathrm{E}+2$ \\
\hline $\mathrm{W}^{29+}$ & $1.319 \mathrm{E}-1$ & $2.030 \mathrm{E}+0$ & $6.638 \mathrm{E}-1$ & $6.176 \mathrm{E}+1$ & $6.983 \mathrm{E}+0$ & $1.997 \mathrm{E}+2$ & $1.976 \mathrm{E}+1$ & $5.484 \mathrm{E}+2$ \\
\hline $\mathrm{W}^{35+}$ & $1.353 \mathrm{E}+1$ & $1.906 \mathrm{E}+2$ & $5.528 \mathrm{E}+1$ & $1.919 \mathrm{E}+2$ & $5.820 \mathrm{E}+2$ & $2.271 \mathrm{E}+2$ & $-4.814 \mathrm{E}+1$ & $7.170 \mathrm{E}+1$ \\
\hline $\mathrm{W}^{37+}$ & $1.902 \mathrm{E}+3$ & $1.597 \mathrm{E}+1$ & $7.153 \mathrm{E}+2$ & $1.211 \mathrm{E}+2$ & $2.698 \mathrm{E}+2$ & $9.729 \mathrm{E}-1$ & $4.544 \mathrm{E}+1$ & $5.296 \mathrm{E}+0$ \\
\hline $\mathrm{W}^{38+}$ & $1.864 \mathrm{E}+3$ & $1.221 \mathrm{E}+1$ & $7.125 \mathrm{E}+2$ & $2.672 \mathrm{E}+0$ & $2.545 \mathrm{E}+2$ & $3.542 \mathrm{E}+1$ & $-1.132 \mathrm{E}+0$ & $1.056 \mathrm{E}+2$ \\
\hline$W^{39+}$ & $2.554 \mathrm{E}+2$ & $1.453 \mathrm{E}+1$ & $1.959 \mathrm{E}+3$ & $7.767 \mathrm{E}+2$ & $1.079 \mathrm{E}+2$ & $3.930 \mathrm{E}+1$ & $6.444 \mathrm{E}-1$ & $4.854 \mathrm{E}+0$ \\
\hline $\mathrm{W}^{41+}$ & $2.372 \mathrm{E}+1$ & $2.304 \mathrm{E}+2$ & $7.496 \mathrm{E}+1$ & $-1.253 \mathrm{E}+1$ & $1.811 \mathrm{E}+3$ & $6.989 \mathrm{E}+2$ & $6.467 \mathrm{E}+0$ & $1.241 \mathrm{E}+0$ \\
\hline$W^{42+}$ & $2.031 \mathrm{E}+3$ & $2.822 \mathrm{E}+0$ & $9.069 \mathrm{E}+2$ & $1.091 \mathrm{E}+2$ & $3.038 \mathrm{E}+2$ & $4.457 \mathrm{E}+1$ & $1.238 \mathrm{E}+1$ & $-7.289 \mathrm{E}-1$ \\
\hline $\mathrm{W}^{43+}$ & $2.015 \mathrm{E}+3$ & $1.508 \mathrm{E}+0$ & $2.466 \mathrm{E}+2$ & $8.819 \mathrm{E}+0$ & $8.080 \mathrm{E}+1$ & $8.206 \mathrm{E}+2$ & $-4.228 \mathrm{E}+0$ & $2.841 \mathrm{E}+1$ \\
\hline $\mathrm{W}^{44+}$ & $9.994 \mathrm{E}+2$ & $4.126 \mathrm{E}+1$ & $3.618 \mathrm{E}+2$ & $-2.928 \mathrm{E}+0$ & $2.154 \mathrm{E}+3$ & $1.230 \mathrm{E}+2$ & $1.694 \mathrm{E}+0$ & $1.152 \mathrm{E}+1$ \\
\hline$W^{45+}$ & $1.280 \mathrm{E}-1$ & $3.430 \mathrm{E}+0$ & $1.610 \mathrm{E}+2$ & $1.000 \mathrm{E}+1$ & $1.905 \mathrm{E}+3$ & $4.352 \mathrm{E}+1$ & $6.110 \mathrm{E}-1$ & $6.498 \mathrm{E}+2$ \\
\hline$W^{46+}$ & $1.255 \mathrm{E}+0$ & $2.049 \mathrm{E}+0$ & $2.540 \mathrm{E}+0$ & $2.610 \mathrm{E}+2$ & $1.312 \mathrm{E}+3$ & $6.421 \mathrm{E}+1$ & $2.587 \mathrm{E}+2$ & $1.006 \mathrm{E}+1$ \\
\hline $\mathrm{W}^{47+}$ & $4.845 \mathrm{E}-1$ & $6.765 \mathrm{E}+0$ & $2.572 \mathrm{E}-1$ & $9.846 \mathrm{E}+1$ & $1.636 \mathrm{E}+0$ & $2.502 \mathrm{E}+1$ & $1.398 \mathrm{E}+3$ & $3.607 \mathrm{E}+2$ \\
\hline $\mathrm{w}^{56+}$ & $5.043 \mathrm{E}+3$ & $2.154 \mathrm{E}+1$ & $2.865 \mathrm{E}+2$ & $1.331 \mathrm{E}+3$ & $7.638 \mathrm{E}+1$ & $-5.745 \mathrm{E}+0$ & $3.613 \mathrm{E}+0$ & $2.557 \mathrm{E}+0$ \\
\hline $\mathrm{W}^{57+}$ & $5.022 \mathrm{E}+3$ & $1.639 \mathrm{E}+1$ & $3.147 \mathrm{E}+2$ & $2.922 \mathrm{E}+0$ & $8.806 \mathrm{E}+1$ & $1.527 \mathrm{E}+1$ & $1.392 \mathrm{E}+3$ & $3.331 \mathrm{E}+0$ \\
\hline $\mathrm{W}^{58+}$ & $2.318 \mathrm{E}+3$ & $5.519 \mathrm{E}+1$ & $5.547 \mathrm{E}+2$ & $2.195 \mathrm{E}+1$ & $1.739 \mathrm{E}+2$ & $7.181 \mathrm{E}+3$ & $5.191 \mathrm{E}+0$ & $2.424 \mathrm{E}+0$ \\
\hline $\mathrm{W}^{59+}$ & $1.390 \mathrm{E}+3$ & $5.377 \mathrm{E}+0$ & $3.186 \mathrm{E}+2$ & $6.463 \mathrm{E}+1$ & $5.575 \mathrm{E}+3$ & $8.097 \mathrm{E}+0$ & $-9.345 \mathrm{E}+0$ & $1.825 \mathrm{E}+0$ \\
\hline $\mathrm{W}^{60+}$ & $5.927 \mathrm{E}+3$ & $2.479 \mathrm{E}+1$ & $1.698 \mathrm{E}+3$ & $5.867 \mathrm{E}+0$ & $1.354 \mathrm{E}+2$ & $5.810 \mathrm{E}+0$ & $2.080 \mathrm{E}+0$ & $4.203 E+2$ \\
\hline $\mathrm{W}^{61+}$ & $6.231 \mathrm{E}+3$ & $2.340 \mathrm{E}+1$ & $1.690 \mathrm{E}+3$ & $3.421 \mathrm{E}+2$ & $8.422 \mathrm{E}+1$ & $-9.387 \mathrm{E}+0$ & $-4.779 \mathrm{E}+0$ & $3.590 \mathrm{E}+0$ \\
\hline$W^{62+}$ & $7.549 \mathrm{E}+3$ & $1.812 \mathrm{E}+2$ & $2.975 \mathrm{E}+3$ & $2.439 \mathrm{E}+1$ & $5.670 \mathrm{E}+2$ & $6.311 \mathrm{E}+0$ & $3.563 \mathrm{E}+0$ & $3.105 E+1$ \\
\hline$W^{63+}$ & $2.048 \mathrm{E}+3$ & $7.705 \mathrm{E}+0$ & $3.364 \mathrm{E}+2$ & $2.003 \mathrm{E}+1$ & $9.800 \mathrm{E}+1$ & $5.648 \mathrm{E}+0$ & $-2.138 \mathrm{E}+0$ & $6.490 \mathrm{E}+3$ \\
\hline $\mathrm{W}^{64+}$ & $2.287 \mathrm{E}+3$ & $4.734 \mathrm{E}+3$ & $2.317 \mathrm{E}+3$ & $3.701 \mathrm{E}+3$ & $2.367 \mathrm{E}+3$ & $4.719 \mathrm{E}+3$ & $4.708 \mathrm{E}+3$ & $8.999 E+3$ \\
\hline $\mathrm{W}^{65+}$ & $-7.242 \mathrm{E}+1$ & $1.267 \mathrm{E}+1$ & $9.867 \mathrm{E}+0$ & $2.767 \mathrm{E}+3$ & $-1.678 \mathrm{E}+1$ & $7.213 \mathrm{E}+3$ & $2.703 \mathrm{E}+2$ & $9.510 \mathrm{E}+2$ \\
\hline $\mathrm{w}^{66+}$ & $8.095 E+3$ & $3.439 \mathrm{E}+0$ & $3.379 \mathrm{E}+3$ & $2.259 \mathrm{E}+2$ & $1.617 \mathrm{E}+0$ & $2.692 \mathrm{E}+1$ & $1.196 \mathrm{E}+2$ & $1.029 \mathrm{E}+3$ \\
\hline$W^{67+}$ & $7.057 \mathrm{E}+3$ & $3.829 \mathrm{E}+0$ & $1.083 \mathrm{E}+1$ & $1.948 \mathrm{E}+3$ & $1.102 \mathrm{E}+1$ & $4.616 \mathrm{E}+2$ & $3.078 \mathrm{E}+1$ & $1.132 \mathrm{E}+2$ \\
\hline$W^{68+}$ & $5.945 \mathrm{E}+1$ & $2.997 \mathrm{E}+0$ & $5.564 \mathrm{E}+3$ & $-1.524 \mathrm{E}+1$ & $1.357 \mathrm{E}+0$ & $8.009 E+2$ & $1.860 \mathrm{E}+1$ & $4.377 \mathrm{E}+0$ \\
\hline $\mathrm{W}^{69+}$ & $7.536 \mathrm{E}+3$ & $3.170 \mathrm{E}+0$ & $-2.069 \mathrm{E}+0$ & $5.380 \mathrm{E}+2$ & $1.773 \mathrm{E}+1$ & $1.856 \mathrm{E}+3$ & $2.202 \mathrm{E}+1$ & $1.135 \mathrm{E}+2$ \\
\hline $\mathrm{W}^{70+}$ & $5.688 \mathrm{E}+2$ & $7.649 \mathrm{E}+0$ & $2.107 \mathrm{E}+4$ & $7.725 \mathrm{E}+0$ & $2.745 \mathrm{E}+3$ & $7.847 \mathrm{E}+0$ & $1.171 \mathrm{E}+2$ & $2.345 E+1$ \\
\hline $\mathrm{W}^{71+}$ & $1.250 \mathrm{E}+2$ & $3.697 \mathrm{E}+0$ & $1.440 \mathrm{E}+1$ & $7.734 \mathrm{E}+3$ & $5.022 \mathrm{E}+4$ & $1.639 \mathrm{E}+3$ & $4.461 \mathrm{E}+2$ & $2.329 \mathrm{E}+1$ \\
\hline $\mathrm{W}^{72+}$ & $4.563 \mathrm{E}+4$ & $2.734 \mathrm{E}+5$ & $4.563 \mathrm{E}+4$ & $4.563 \mathrm{E}+4$ & $4.563 \mathrm{E}+4$ & $4.563 \mathrm{E}+4$ & $1.635 \mathrm{E}+4$ & $4.563 \mathrm{E}+4$ \\
\hline$W^{73+}$ & $2.424 \mathrm{E}+5$ & $2.933 \mathrm{E}+3$ & $7.716 \mathrm{E}+4$ & $5.084 \mathrm{E}+4$ & $5.344 \mathrm{E}+5$ & $5.084 \mathrm{E}+4$ & $2.019 \mathrm{E}+4$ & $5.084 \mathrm{E}+4$ \\
\hline
\end{tabular}

